\title{
Optimization of the configuration of the anion Selectrodialysis Stack for Fractionation of Phosphate from UASB effluent in Batch Mode on Lab Scale and Pilot Scale.
}

\author{
K. Ghyselbrecht ${ }^{\mathrm{a}}$, A. Jongbloet ${ }^{\mathrm{a}, \mathrm{b}}$, L. Pinoy ${ }^{\mathrm{b}}$, B. Meesschaert ${ }^{\mathrm{a} *}$, \\ a Department of Microbial and Molecular Systems, Faculty of Engineering Technology, KU \\ Leuven Bruges campus, Spoorwegstraat 12, 8200 Brugge, Belgium - \\ boudewijn.meesschaert@kuleuven.be \\ ${ }^{\mathrm{b}}$ Department of Chemical Engineering, Faculty of Engineering Technology, KU Leuven \\ Ghent Technology Campus, Gebroeders De Smetstraat 1, 9000 Gent, Belgium - \\ luc.pinoy@kuleuven.be
}

*: Corresponding author. Tel.: +32 50664852.
Email address: boudewijn.meesschaert@kuleuven.be

\begin{abstract}
In anion selectrodialysis (aSED) multivalent anions are entrapped in the so called "product stream" between a standard anion exchange membrane (SA membrane) and a monovalent anion selective membrane (MVA membrane). This study was carried out on nitrified and ultra-filtrated effluent of an upflow anaerobic sludge blanket reactor (UASB) of a potato processor. The selectivity for phosphate of various membranes that could act as SA membranes was tested on lab scale. From the calculated selectivities and current efficiencies for phosphate transport two membranes, the Fujifilm Type 1 membrane and the PC-Acid 100 OT membrane from PCA are good candidates to replace the previously used PC-SA membrane from PCA. Lowering the $\mathrm{pH}$ had a negative effect on the mobility of the phosphate ions and it is proposed that the $\mathrm{HPO}_{4}{ }^{2-}$ is the ion that migrates through the SA membrane. Increasing the voltage resulted in a better phosphate mobility through the PC-Acid 100 OT membrane. Also, on pilot scale the PC-Acid 100 OT membrane performed much better than the PC-SA membrane: the current efficiency for phosphate transport was higher whereas the current efficiency for DIC transport was lower with the PC-Acid 100 OT membrane than with the PCSA membrane. The PC ACID 100 OT is recommended as standard anion exchange membrane in pilot and full scale stacks for recovery of phosphate by aSED.
\end{abstract}

Keywords: anion exchange membranes; monovalent anion selective membranes, phosphate recovery; selectrodialysis; upscaling; phosphate recovery 


\section{Introduction}

The world reserves of phosphate are declining and various methods are considered to recover it from wastewater and incinerated sludge ashes [1], from which the recovery as struvite is probably the most known [2]. Recovery as calcium phosphate or its crystalline counterpart has however also its potential, as these compounds can be mixed with mined phosphorous ores and treated together to produce phosphoric acid $[3,4]$. For both, the recovery of phosphate as struvite or as calcium phosphate, the concentration of phosphate in the wastewater must be high enough and the suggested concentrations are between 40 and $100 \mathrm{mg} . \mathrm{L}^{-1}$ expressed as phosphate-P $[5,6]$.
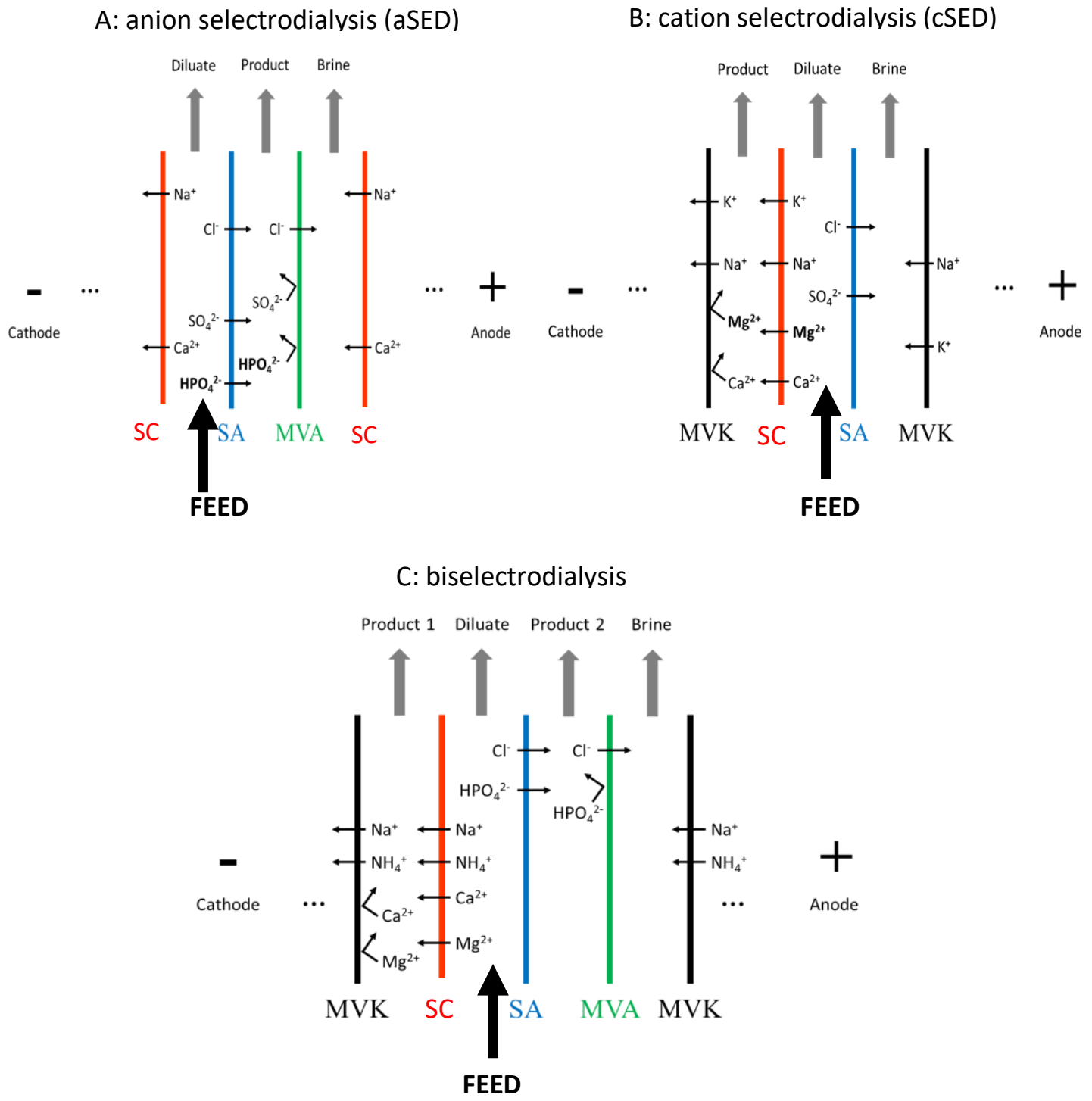

Figure 1: A: outline of the stack for anion selectrodialysis: anions in the feed migrate to the anode. Monovalent anions can permeate the monovalent anion selective membrane (MVA membrane), while polyvalent anions cannot; the latter accumulate between the two anion selective membranes. B: idem for the stack for cation selectrodialysis: cations migrate to the cathode. Monovalent cations migrate through the monovalent cation selective membrane and polyvalent ions accumulate in the product stream. C: outline of the stack for biselectrodialysis: monovalent ions are passing the standard selective membranes but are retained by the monovalent selective membranes. 
A new method for fractionation of multivalent anions from wastewater which is a modification of classic electrodialysis was proposed by Zhang et al. [7]. It is further designated as anion selective electrodialysis or in short anion selectrodialysis (aSED). In this method a monovalent anion exchange membrane (MVA membrane) is mounted in the classic cell pair for electrodialysis between the standard cation exchange membrane (SC membrane) and the standard anion exchange membrane (SA membrane). In this way and compared to classic electrodialysis which is a two compartment system, a three compartment system is obtained. The concentrate, as known from classic electrodialysis, is in fact deduplicated in two streams: one with the multivalent anions, between the SA membrane and the MVA membrane and one which corresponds with the classic concentrate or brine, with only the monovalent anions, between the MVA membrane and the SC membrane; Figure 1A.

Zhang et al. [8] and Liu et al. [9] applied this method for the fractionation of phosphate from synthetic wastewaters. The method is based on the assumption that phosphate occurs as a multivalent ion $\left(\mathrm{HPO}_{4}{ }^{2-}\right)$ above a pH of 7.2 (Figure 2; [10]) and thus that it accumulates between the two anion selective membranes. As this first concentrate is the water stream of interest it is further designated as 'product stream'; see Figure 1A. From this product stream the phosphate was recovered as struvite [8]. Tran et al., [11] used a combination of aSED and precipitation of the fractionated phosphate as calcium phosphate in a pellet reactor to recover phosphorus.

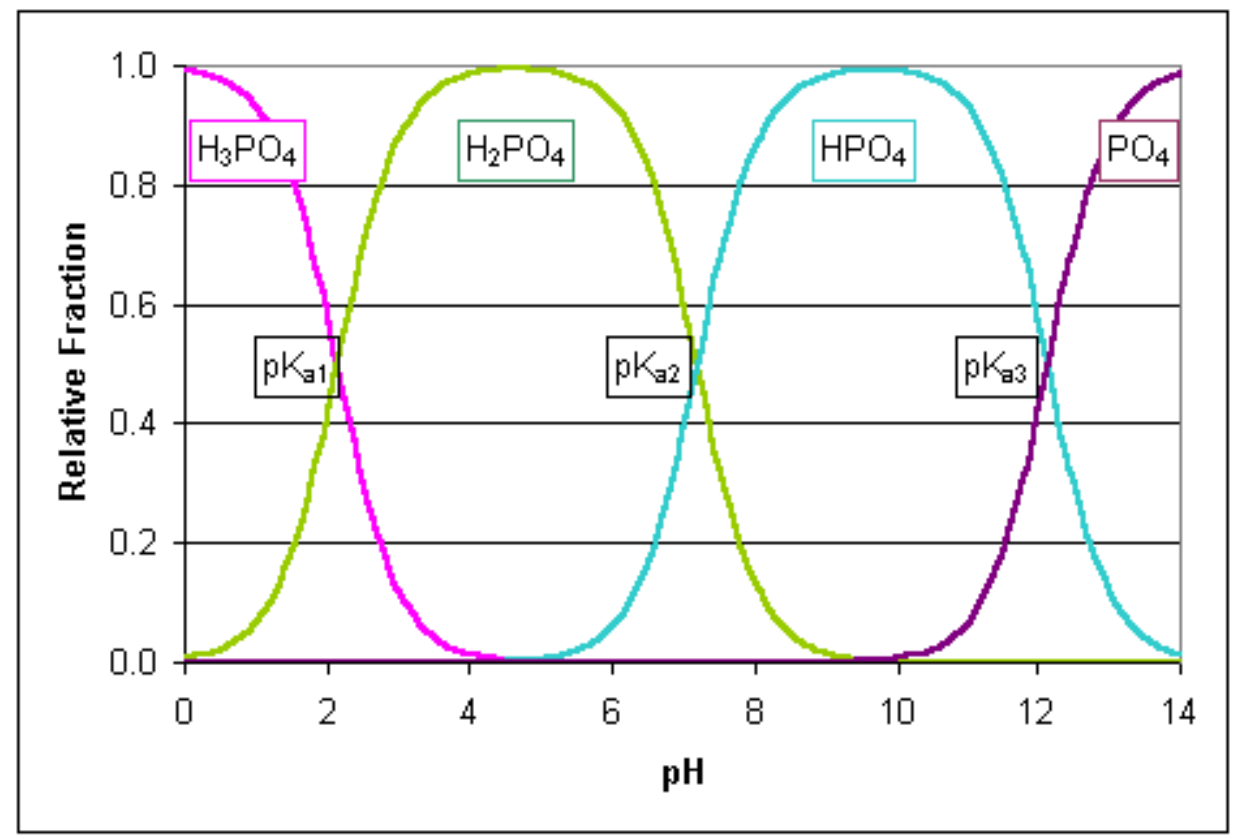

Figure 2: Dissociation of phosphate as function of $\mathrm{pH}[10]$. Above $\mathrm{pKa}_{2}(\mathrm{pH}=7.2)$ most of the phosphate occurs as the multivalent ion $\mathrm{HPO}_{4}{ }^{2-}$ (monohydrogen phosphate).

The idea of modifying the classic stack for electrodialysis for more specified purposes was further elaborated by Ye et al. [12] and Ghyselbrecht et al. [13] which build a stack for cation selective electrodialysis (cSED); Figure 1B. They modified the classic stack by adding an extra monovalent cation selective membrane (MVC membrane), which was mounted at the anodic side of the SA membrane. This modification was successfully applied for isolation of magnesium from seawater in the frame of its use for the recovery of phosphate as struvite $[12,13]$. 
A further elaboration of the stack for electrodialysis was realized by Ye et al. [14]: they combined in one stack the aSED and cSED principle by mounting in the stack as well MVC membranes as MVA membranes; Figure 1C. This modification of electrodialysis was designated as biselectrodialysis. When the ions move from the feed to the electrodes, the cations, respectively the anions, first meet the standard membranes which allows them to pass and then they are confronted with the monovalent selective membranes that are selectively permeable for the monovalent ions. In this way two product streams are obtained, and the system is converted in to a four-compartment system. The system was applied on simulated swine manure for the recovery of bivalent cations $\left(\mathrm{Ca}^{2+}, \mathrm{Mg}^{2+}\right)$ in the cation product stream 1 and of phosphate in the anion product stream 2. Combination of both product streams leads to the recovery of phosphate with the endogenous bivalent ions of the manure, thus without the consumption of an extra magnesium or calcium source [14].

For both aSED and biselectrodialysis the concentration of phosphate that can be obtained in the product stream respectively in the anion product stream is determined by the permeability of the membranes flanking the product stream in the stack. To retain the multivalent ions such as $\mathrm{HPO}_{4}{ }^{2-}$ in the product streams, the MVA membranes should be completely impermeable for them. From the experiments as described by Zhang et al. [8] with synthetic wastewaters this prerequisite is apparently fulfilled: phosphate ions do not permeate the previously used PCMVA membrane. Pilot studies either in the batch mode or in the feed and bleed mode showed however that the concentrations that could be obtained in the product stream were low [15]. All available experimental evidence led to the conclusion that the transport of phosphate from the feed compartments to the product compartments through the previously used PC-SA membrane is slow and incomplete. The PC-SA membrane behaves apparently as a kind of MVA membrane which has as result that the current efficiency for phosphate transport is too low.

In order to obtain high concentrations of multivalent ions such as phosphate in the product stream it is thus evident that their transport through the SA membrane should not be hindered. As discussed in Zhang et al. [16], standard anion exchange membranes do show a selectivity towards monovalent ions, which is unwanted for the application under investigation here. This selectivity is influenced by $\mathrm{pH}$ (when dealing with weak acids) and is also at least partly attributed to a size-exclusion effect. In this way, thinner membranes with a lower electrical resistance and/or showing bigger pore sizes should be used preferably in applications whereby the selectivity towards monovalent ions should be as low as possible. Before pilot scale studies were further explored for the recovery of phosphate from real wastewater it was investigated how phosphate transport through the SA membrane at lab scale can be maximized. The best experimental conditions with the best performing membrane are then further explored on pilot scale.

To make the results of our experiments useful in an industrial environment real wastewater from a potato processing plants was used. In potato processing companies a large part of the phosphate in the untreated wastewater finds its origin in the use of pyrophosphate that is added during blanching of the potatoes to prevent discoloration. Further, in most of this companies, an upflow anaerobic sludge blanket reactor (UASB) is in operation with or without simultaneous recuperation of biogas. The best place to recover phosphate during wastewater treatment is after this anaerobic treatment [1]. During this anaerobic treatment an extensive mineralization of organic material occurs, and polyphosphates and nucleic acids are hydrolysed, 
and phosphate is set free. The phosphate in the UASB effluent of a potato processor thus originates from the added pyrophosphate and from the mineralization of organic material.

The anaerobic treatment and the simultaneous formation of biogas, which is a mixture of methane $\left(\mathrm{CH}_{4}\right)$ and carbon dioxide $\left(\mathrm{CO}_{2}\right)$ leads to high amounts of dissolved inorganic carbon (DIC) in the UASB effluent: carbon dioxide reacts with water to carbonic acid, which dissociates to bicarbonate $\left(\mathrm{pKa}_{1}=6.05\right)$. As such part of the hydroxylic alkalinity is converted to bicarbonate alkalinity. During normal electrodialysis anions and cations concentrate in the brine and (bi)carbonate easily leads to scaling of the membranes especially if the feed to be treated also contains bivalent cations [17]. During aSED the (bivalent) cations are concentrated in the brine and bicarbonate as monovalent anion should also accumulate in the brine. Under these conditions carbonate scaling is expected to occur especially if the $\mathrm{pH}$ would increase. To avoid this scaling the USAB effluent was first subjected to a aeration and nitrification to remove as much as possible of the DIC. Relative to the concentration of ammonium present in the wastewater a bimolecular amount of bicarbonate is consumed by the protons that are formed during the nitrification $[3,4]$.

$$
\begin{aligned}
& 2 \mathrm{NH}_{4}^{+}+4 \mathrm{O}_{2} \rightarrow 2 \mathrm{NO}_{3}{ }^{-}+2 \mathrm{H}_{2} \mathrm{O}+4 \mathrm{H}^{+} \\
& 4 \mathrm{HCO}_{3}^{-}+4 \mathrm{H}^{+} \rightarrow 4 \mathrm{H}_{2} \mathrm{CO}_{3} \rightarrow 4 \mathrm{H}_{2} \mathrm{O}+4 \mathrm{CO}_{2} \uparrow \\
\text { Sum: } & 2 \mathrm{NH}_{4}^{+}+4 \mathrm{O}_{2}+4 \mathrm{HCO}_{3}^{-} \rightarrow 2 \mathrm{NO}_{3}^{-}+6 \mathrm{H}_{2} \mathrm{O}+4 \mathrm{CO}_{2} \uparrow
\end{aligned}
$$

\section{Material and Methods}

\subsection{Origin of the wastewater}

The effluent of the UASB of Agristo, a potato processor in Wielsbeke, Belgium was subjected to a preceding settlement in two coupled international bulk containers (IBC's). The containers were interconnected at a height of $80 \mathrm{~cm}$; see Figure 3A.
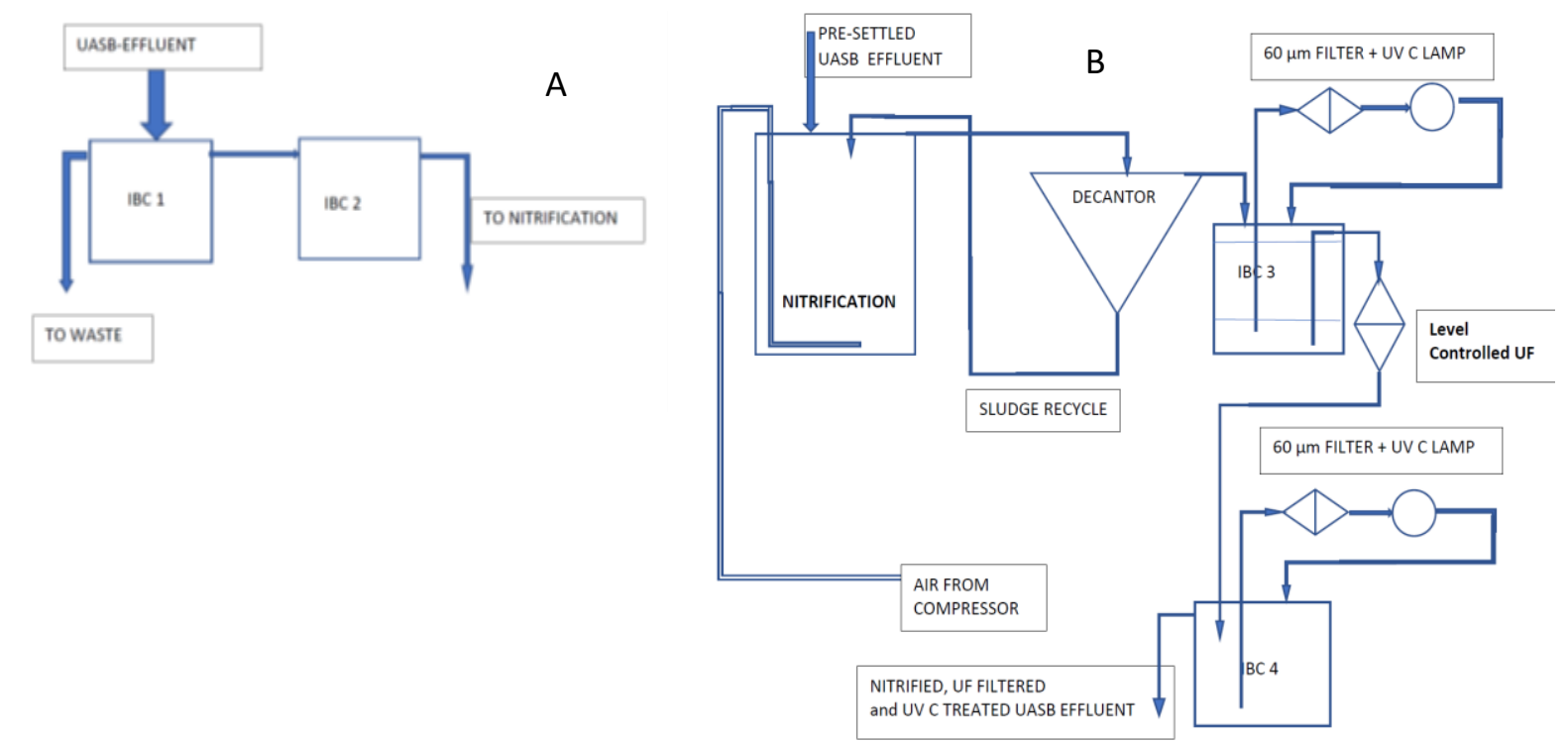

Figure 3: schematic representation of the pre-treatment of the UASB effluent. A: the pre-settling step; B: the subsequent nitrification and an ultrafiltration. The ultra-filtrate was used for the lab scale and pilot scale selectrodialysis experiments.

The UASB effluent was fed to the first IBC and the excess spilled over to the wastewater treatment facility of the company. With a peristaltic pump pre-settled effluent was pumped from 
the second IBC to a $1.5 \mathrm{~m}^{3}$ reactor for nitrification. The flow to the reactor was $55-60 \mathrm{~L} \cdot \mathrm{h}^{-1}$ and consequently the HRT in IBC 2 and in the nitrification reactor was about 14 hours and about one day. The aeration of the reactor was done with compressed air and the flow was just high enough to obtain full conversion of ammonium to nitrate. The reactor spilled over in a decanter on which a sludge recycle $\left(150{\mathrm{~L} . \mathrm{h}^{-1}}^{-1}\right.$ was installed. The decanter itself spilled over to a third IBC. To avoid an eventual contamination with bulky sludge the nitrified wastewater was subjected to an ultrafiltration using a Inge Dizzer P UF module from BASF. Both the feed (IBC 3) and the filtrate (IBC 4) of the UF were circulated over a $60 \mu \mathrm{m}$ candle filter and a UV C lamp (Clear Pond; 18 Watt). This nitrified, ultra-filtrated and UV C treated UASB effluent ( $\mathrm{pH}=7.47 \pm 0.09$ ) was used as feed in the lab scale and pilot scale experiments Figure $3 \mathrm{~B}$ summarizes the further pre-treatment steps.

\subsection{Electrodialysis equipment}

The lab scale equipment was a ED-64-004 stack of PCCell GmbH (Heusweiler, Germany) with 5 cell triplets which was described previously [7,8]. The membrane surface was $0.0064 \mathrm{~m}^{2}$ for every membrane and the equipment was operated in the batch modus and mostly at $10 \mathrm{~V}$. This setting was calculated as the sum of an expected voltage drop of $0.5 \mathrm{~V}$ over every active compartment and of $2.5 \mathrm{~V}$ for the electrode compartments. MVA membranes (PC-MVA), SC membranes (PC-SK), and end SC membranes (PC-SC) from PCA (Heusweiler, Germany) were used. At first, the standard PC-SA membrane from PCA was used as SA membrane as in the references mentioned above [7,8]. Secondly, various SA membranes were tested in combination with the PC-MVA membrane. The latter has a proven selectivity towards monovalent anions and retains fully the multivalent anions when used with synthetic wastewaters [7,8]. Concerning the standard membranes, besides the reference PC-SA membrane from PCA, the PC-ACID 100, the PC-ACID 100 OT and the PC-400D membranes were selected, all also from PCA. The first one is especially developed to transport the relatively big sulphate ions in acidic environments, while the other two were advised by the supplier because of their bigger pore size. The Fujifilm membranes were chosen as they are relatively thin membranes with a rather small (and different) electrical resistance. The Fumatech FAS-PET-130 membrane was also chosen because of its supposed bigger pore size. Table 1 summarizes what is known about the properties of the membranes.

At the start of each experiment the product and the concentrate solutions were respectively 0.75 $\mathrm{M}$ and $0.15 \mathrm{M} \mathrm{NaCl}$; as such the diluate stream had the lowest conductivity and determinates the current of the stack. During anion selectrodialysis electroneutrality in the product compartment, which is entrapped between two anion selective membranes, is realized by expulsion of anions to the concentrate compartment, since the cations cannot migrate. In this context the ionic strength in the product compartment must be high enough. The volumes of the feed, product and concentrate were 4, 1 and 1 litre respectively and they were circulated at a flow rate of $30 \mathrm{~L} . \mathrm{h}^{-1}$. By using a larger feed volume than product and concentrate volume, migrating ions are concentrated in the latter and the results are more pronounced. Since its concentration is continuously decreasing during the experimental procedure, the feed under treatment is also indicated as the diluate. Performing batch experiments means that the diluate, brine and product were recirculated through the installation until a desalination degree of the diluate of approximately $90 \%$ (based on the conductivity) was achieved. In this context the 
experiments lasted for about 3 hours. $2 \mathrm{~L}$ of $0.5 \mathrm{M} \mathrm{NaNH}_{2} \mathrm{SO}_{3}$ was used as electrode rinsing solution (ERS) and it was circulated at $150 \mathrm{~L} \cdot \mathrm{h}^{-1}$.

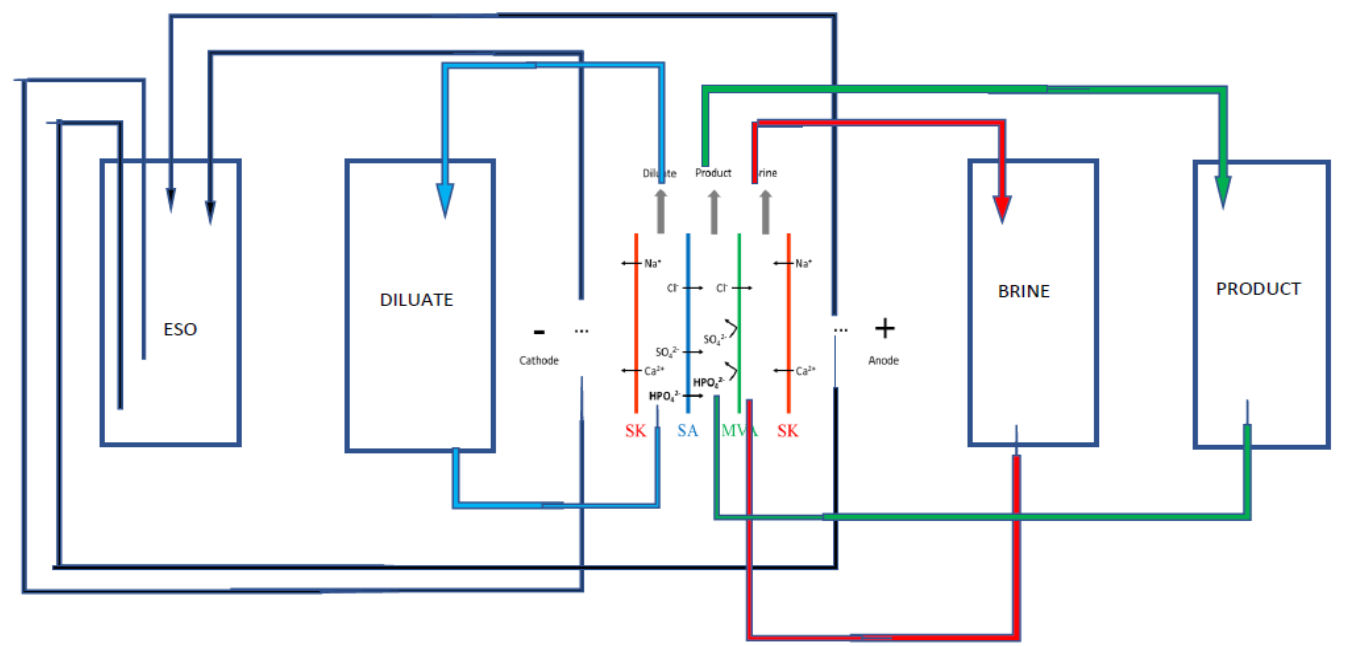

Figure 4: Schema of the circulating fluids in the equipment for electrodialysis.

The pilot stack contained 20 triplets of membranes.

The pilot scale equipment which was used was that described by Ghyselbrecht et al. [13], except that an EDQ stack (PCCell GmbH, Heisweiler, Germany) for aSED was used, thus with the membrane arrangement as in Figure 1A (and not that of Figure 1B). The setup consisted of four $200 \mathrm{~L}$ vessels for the diluate, product, brine and ERS; thus, resulting in four separate loops; see Figure 4. MVA membranes (PC-MVA), SC membranes (PC-SK), end SC membranes (PC-SC) and SA membranes (either PC-SA or PC-ACID 100 OT) were installed in the EDQ stack. The stack consisted of 20 cell triplets, so in total 20 pieces of PC-SA or PC-ACID 100 OT, 20 pieces of PC-MVA, 19 pieces of PC-SK and 2 pieces of PC-SC were used.

Table 1. Overview of the characteristics of the membranes

\begin{tabular}{|c|c|c|c|c|}
\hline Type of membrane & $\begin{array}{c}\text { Functional } \\
\text { group }\end{array}$ & $\begin{array}{c}\text { Thickness } \\
(\mu \mathrm{m})\end{array}$ & Perm-selectivity & $\begin{array}{c}\text { Electrical } \\
\text { resistance } \\
\left(\Omega \mathrm{cm}^{2}\right)\end{array}$ \\
\hline PCA PC-SA & $-\mathrm{NR}_{3}{ }^{+}$ & $180-220$ & $>0.95$ & \\
\hline PCA PC-ACID 100 & $-\mathrm{NR}_{3}{ }^{+}$ & $100-110$ & Unknown & Unknown \\
\hline PCA PC-ACID 100 OT & Unknown $^{+}$ & Unknown & Unknown & Unknown \\
\hline PCA PC-400 D & $-\mathrm{NR}_{3}{ }^{+}$ & $160-200$ & $>0.98$ & \pm 10 \\
\hline Fumatech FAS-PET-130 & $-\mathrm{NR}_{3}{ }^{+}$ & $120-140$ & $0.93-0.97$ & $1.7-3.0$ \\
\hline Fujifilm Type 1 & $-\mathrm{NR}_{3}{ }^{+}$ & 125 & 0.92 & 1.3 \\
\hline Fujifilm Type 10 & $-\mathrm{NR}_{3}{ }^{+}$ & 125 & 0.95 & 1.7 \\
\hline PCA PC-MVA & $-\mathrm{NR}_{3}{ }^{+}$ & 110 & $>0.97$ & 20 \\
\hline PCA PC-SK & $-\mathrm{SO}_{3}{ }^{-}$ & $160-200$ & $>0.95$ & 2.5 \\
\hline PCA PC-SC & $-\mathrm{SO}_{3}{ }^{-}$ & 400 & $>0.94$ & 9 \\
\hline
\end{tabular}

All the membranes mentioned were supplied by PCA (PolymerChemie Altmeier GmbH, Heusweiler, Germany). For each membrane, the active surface area was $0.038 \mathrm{~m}^{2}$ and the spacer thickness between two membranes was $0.5 \mathrm{~mm}$. Compared to the lab scale, this pilot scale 
represented thus an upscaling of about 24 times. An overview of the characteristics of all the membranes used, which were provided by the manufacturers, is given in Table 1 .

$200 \mathrm{~L}$ of nitrified effluent sent through the UF was used as initial diluate. The initial brine and product respectively consisted of $200 \mathrm{~L}$ of $0.075 \mathrm{M} \mathrm{NaCl}$ and $50 \mathrm{~L} 0.15 \mathrm{M} \mathrm{NaCl}$. The used volumes imply that the compounds that migrate from the diluate to the product are upconcentrated. 100 litre of $0.5 \mathrm{M} \mathrm{Na}_{2} \mathrm{NH}_{2} \mathrm{SO}_{3}$ was used as ERS. A constant voltage of $25 \mathrm{~V}$ was applied. This was deduced as follows: for each cell triplet a voltage drop of $1.25 \mathrm{~V}$ was estimated. In view of further long-term experiments in which constant supervision is not possible, a somewhat lower voltage drop was applied than in the lab tests. During the batch experiments, the diluate, brine, product and ERS were recirculated with a flow rate of 400, 400, 400 and 600 L.h ${ }^{-1}$, respectively. The chosen flow rates are in line with the guidelines of the stack manufacturer, in this way assuring optimal hydrodynamic conditions inside the stack. The experiments lasted four hours.

\subsection{Experimental set up}

At first experiments were carried out with the stack as it was assembled in the previous experiments and in which synthetic wastewater [7,8] was treated. This is with the PC-SA membrane as standard anion exchange membrane and with PC-MVA membrane as monovalent selective anion exchange membrane, however with the nitrified and ultra-filtrated UASB effluent as feed. The goal was to investigate if the used PC-MVA membrane indeed retained the phosphate in the product stream when treating real wastewater. Also important is to verify where DIC will accumulate, in the product stream or in the brine. In a following step various membranes that could act as SA membrane where investigated for their efficiency in phosphate transport; the membranes and their properties are listed in Table 1. The finally selected membranes were also tested at a lower $\mathrm{pH}$ of the feed $(\mathrm{pH}=6.29)$ to investigate the effect of the speciation of phosphate on its migration and at a higher voltage over the stack $(13.8 \mathrm{~V})$, which corresponds to a voltage drop of $0.75 \mathrm{~V}$ per compartment of the stack.

Also, the performance of the selected anion selective membrane at lab scale, was investigated at pilot scale and its performance was compared with that of initially used PC-SA membrane.

\section{a. Analytical methods}

Samples of the batch experiments were collected at the start of each experiment and then every 30 minutes. The following parameters were analysed: $\mathrm{pH}$, conductivity and chloride, nitrate, phosphate, sulphate, sodium, ammonium, potassium, calcium, magnesium, DIC and TOC concentration. Conductivity was measured with a LF318 conductivity meter (WTW, Germany). The $\mathrm{pH}$ was measured with a S220 SevenCompact $\mathrm{pH}$ benchtop meter equipped with an InLab Expert Pro-ISM electrode (Mettler Toledo, Switzerland). Ion concentrations were measured by means of an ion chromatograph equipped with a conductivity detector (883 Basic IC Plus and 883 Compact Autosampler, Metrohm, Switzerland). For the detection of the cations $\left(\mathrm{Na}^{+}, \mathrm{NH}_{4}{ }^{+}\right.$, $\mathrm{K}^{+}, \mathrm{Ca}^{2+}$ and $\mathrm{Mg}^{2+}$ ) the ion chromatograph was supplied by the combination of a Metrosep C$4-150 / 4.0$ analytical column and Metrosep C-4 Guard/4.0 precolumn with $0.7 \mathrm{mM}$ dipicolinic acid and $1.7 \mathrm{mM} \mathrm{HNO} 3$ as eluent at a constant flow rate of $0.9 \mathrm{~mL} \cdot \mathrm{min}^{-1}$. The anions $\left(\mathrm{Cl}^{-}, \mathrm{NO}_{3}^{-}\right.$ 
, $\mathrm{PO}_{4}{ }^{3-}$ and $\mathrm{SO}_{4}{ }^{2-}$ ) were separated on a Metrosep A Supp 5 150/4.0 analytical column and Metrosep A Supp 4/5 Guard precolumn with $3.2 \mathrm{mM} \mathrm{Na}_{2} \mathrm{CO}_{3}$ and $1.0 \mathrm{mM} \mathrm{NaHCO}_{3}$ as eluent at a constant flow rate of $0.7 \mathrm{~mL} \cdot \mathrm{min}^{-1}$. The concentration of DIC and TOC was measured with a TOC Analyzer (TOC-VCPN Total Organic Carbon Analyzer, Shimadzu, Japan).

\section{b. Data Analysis}

The current efficiency of ion A $\left(\eta_{A}\right)$ is defined as the ratio of the electrical charge used for the transport of ion A to the total electrical charge [18] and is calculated by:

$$
\eta_{A}=\frac{\left(\Delta m_{A}(t) / M_{A}\right) z F}{n I(\Delta t)} \times 100(\%)
$$

where $\Delta \mathrm{m}_{\mathrm{A}}(\mathrm{t})$ is the weight of the transferred ion A during the considered time period $(\mathrm{g}), \mathrm{M}_{\mathrm{A}}$ is the molar mass of ion $\mathrm{A}\left(\mathrm{g} \cdot \mathrm{mol}^{-1}\right), \mathrm{z}$ is the valence of ion $\mathrm{A}(-), \mathrm{F}$ is the Faraday constant (96485 C. $\left.\mathrm{mol}^{-1}\right), \Delta \mathrm{t}$ is the time period (s), I is the mean current for that time period (A) and finally $\mathrm{n}$ is the number of cell triplets (-) in the aSED stack. In this study, the current efficiency was calculated at diluate side for the transport through the SA membranes.

Membrane selectivity, represented as separation efficiencies $\left(S_{B}^{A}\right)$, was calculated for the standard anion-exchange membranes (either PC-SA or PC-Acid 100 OT). This was calculated by equation (2) which was developed by Sansen et al. [19].

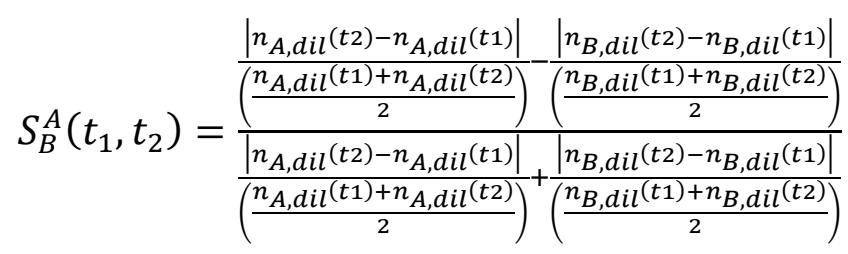

where $S_{B}^{A}$ is the selectivity of the PC-SA/PC-Acid 100 OT membrane ranging between -1 and 1 (if ion A is transported slower than ion $\mathrm{B}, S_{B}^{A}$ will be between -1 and 0 ; if ion B is transported slower than ion $\mathrm{A}, S_{B}^{A}$ will be between 0 and 1$)$. $\mathrm{n}_{\mathrm{A}}$ is the amount of ion $\mathrm{A}(\mathrm{mol}), \mathrm{n}_{\mathrm{B}}$ is the amount of ion $B(\mathrm{~mol}) ; t_{1}$ and $t_{2}$ is the start and end of the period for which the selectivity is calculated. The subscript "dil" is related to the components at the feed (diluate) side of the PCSA/PC-Acid 100 OT membrane.

\section{Results and discussions}

\subsection{Reference experiments with PC-SA membranes}

The composition of the nitrified and ultra-filtered USAB effluent is given in Table 2.

The reference experiment with SA membranes was done in duplo. The results of the two experiments are given in Figure 5, as well for the time course of conductivity, current density and the phosphate and DIC concentration.

In both experiments the $\mathrm{pH}$ of the feed/diluate gradually decreased from 7.5 to 4 , while the $\mathrm{pH}$ of the product increased from 6 to 10 and the $\mathrm{pH}$ from the concentrate dropped from 6 to 2.5. These $\mathrm{pH}$ changes may be inherent to the migration mechanism of phosphate through the anion 
exchange membrane. It is assumed that $\mathrm{H}_{2} \mathrm{PO}_{4}{ }^{-}$deprotonates towards $\mathrm{HPO}_{4}{ }^{2-}$ and that the latter passes the membrane leaving its proton in the diluate. The addition of $\mathrm{HPO}_{4}{ }^{2-}$ results in a $\mathrm{pH}$ increase in the product compartment. The protons, which are very mobile ions, migrate through the diluate to the concentrate (see Figure 1A). These changes in $\mathrm{pH}$ influence the speciation of phosphate and DIC. In the product, the ratio carbonate/bicarbonate will progressively increase $\left(\mathrm{pK}_{\mathrm{a}}=10.3\right)$, while simultaneously the ratio $\mathrm{HPO}_{4}{ }^{2-} / \mathrm{H}_{2} \mathrm{PO}_{4}{ }^{-}$also increases; in the the diluate the ratio $\mathrm{HPO}_{4}{ }^{2-} / \mathrm{H}_{2} \mathrm{PO}_{4}{ }^{-}$decreases in time until almost exclusively $\mathrm{H}_{2} \mathrm{PO}_{4}^{-}$is found $\left(\mathrm{pK}_{\mathrm{a}}=7.09\right.$; Figure 2).

Table 2: composition of the nitrified and ultra-filtered UASB effluent

\begin{tabular}{|c|c|}
\hline & UF filtrate \\
\hline $\mathrm{pH}[-]$ & $7.5 \pm 0.2$ \\
Conductivity $\left[\mathrm{mS} . \mathrm{cm}^{-1}\right]$ & $5.1 \pm 0.1$ \\
$\mathrm{Cl}^{-}\left[\mathrm{mg} \cdot \mathrm{L}^{-1}\right]$ & $336 \pm 20$ \\
$\mathrm{NO}_{3}{ }^{-}-\mathrm{N}\left[\mathrm{mg} . \mathrm{L}^{-1}\right]$ & $351 \pm 17$ \\
$\mathrm{PO}_{4}{ }^{3-}-\mathrm{P}\left[\mathrm{mg} \cdot \mathrm{L}^{-1}\right]$ & $56 \pm 8$ \\
$\mathrm{SO}_{4}{ }^{2-}\left[\mathrm{mg} \cdot \mathrm{L}^{-1}\right]$ & $48 \pm 10$ \\
$\mathrm{Na}^{+}\left[\mathrm{mg} \cdot \mathrm{L}^{-1}\right]$ & $86 \pm 10$ \\
$\mathrm{NH}_{4}^{+}-\mathrm{N}\left[\mathrm{mg} . \mathrm{L}^{-1}\right]$ & $0 \pm 0$ \\
$\mathrm{~K}^{+}\left[\mathrm{mg} \cdot \mathrm{L}^{-1}\right]$ & $1542 \pm 68$ \\
$\mathrm{Ca}^{2+}\left[\mathrm{mg} \cdot \mathrm{L}^{-1}\right]$ & $55 \pm 13$ \\
$\mathrm{Mg}^{2+}\left[\mathrm{mg} \cdot \mathrm{L}^{-1}\right]$ & $62 \pm 6$ \\
$\mathrm{TIC}\left[\mathrm{mg} \cdot \mathrm{L}^{-1} \mathrm{C}\right]$ & $92 \pm 12$ \\
$\mathrm{TOC}\left[\mathrm{mg} \cdot \mathrm{L}^{-1} \mathrm{C}\right]$ & $23 \pm 4$ \\
\hline
\end{tabular}

Figure 5 shows some variation between the two experiments, but this is the consequence of working with real wastewaters; however the two experiments match well. From Figure 5A it is clear that ions are moving to the brine. For a correct interpretation of the results the volume ratio of the diluate to those of the product and the brine, which is four to one, must be considered. The disappearance of ions from the diluate results in an increase of the electrical resistance and the current over the stack decreases; see Figure 5B.

From Figure 5C it is obvious that the phosphate ions move to the product and this without breakthrough to the brine; the MVA perfectly blocks the migration of the (mostly) bivalent phosphate ions, and consequently they accumulate in the product. The behaviour of the DIC is unexpected; see Figure 5D. At the $\mathrm{pH}$ of the pre-treated UASB effluent, $7.5 \pm 0.2$ (Table 2), inorganic carbon occurs as monovalent charged bicarbonate $\left(\mathrm{HCO}_{3}{ }^{-}\right)$and is expected to migrate through the MVA membrane to the brine, at least at the start of the experiment were DIC occurs almost exclusively as bicarbonate. This is not the case, probably as a result of the fact that the hydrated ionic radius of bicarbonate, being $0.364 \mathrm{~nm}$ [20], is larger than the hydrated ionic radius of $\mathrm{HPO}_{4}{ }^{2-}(0.327 \mathrm{~nm})$ and $\mathrm{H}_{2} \mathrm{PO}_{4}{ }^{-}(0.302 \mathrm{~nm})$ [21]. As the $\mathrm{pH}$ increases during the experiment, an increasing part of the DIC will occur as bivalently carbonate, which is expected to be retained by the MVA membrane. However as the $\mathrm{pK}_{\mathrm{a}}$ of bicarbonate is 10.3 , the majority of the DIC will always occur as bicarbonate, even at the highest obtained $\mathrm{pH}(\mathrm{pH}=10)$. In view of the recovery of phosphate from the product stream the simultaneous occurrence of 
bicarbonate is a disadvantage as the latter complicates the recovery of phosphate as pure calcium phosphate $[3,4]$. However, this observation also justifies the applied nitrification as pre-treatment. In doing so the concentration of DIC decreases (see reactions in the introduction) and the amount that can accumulate in the product stream together with phosphate is reduced.
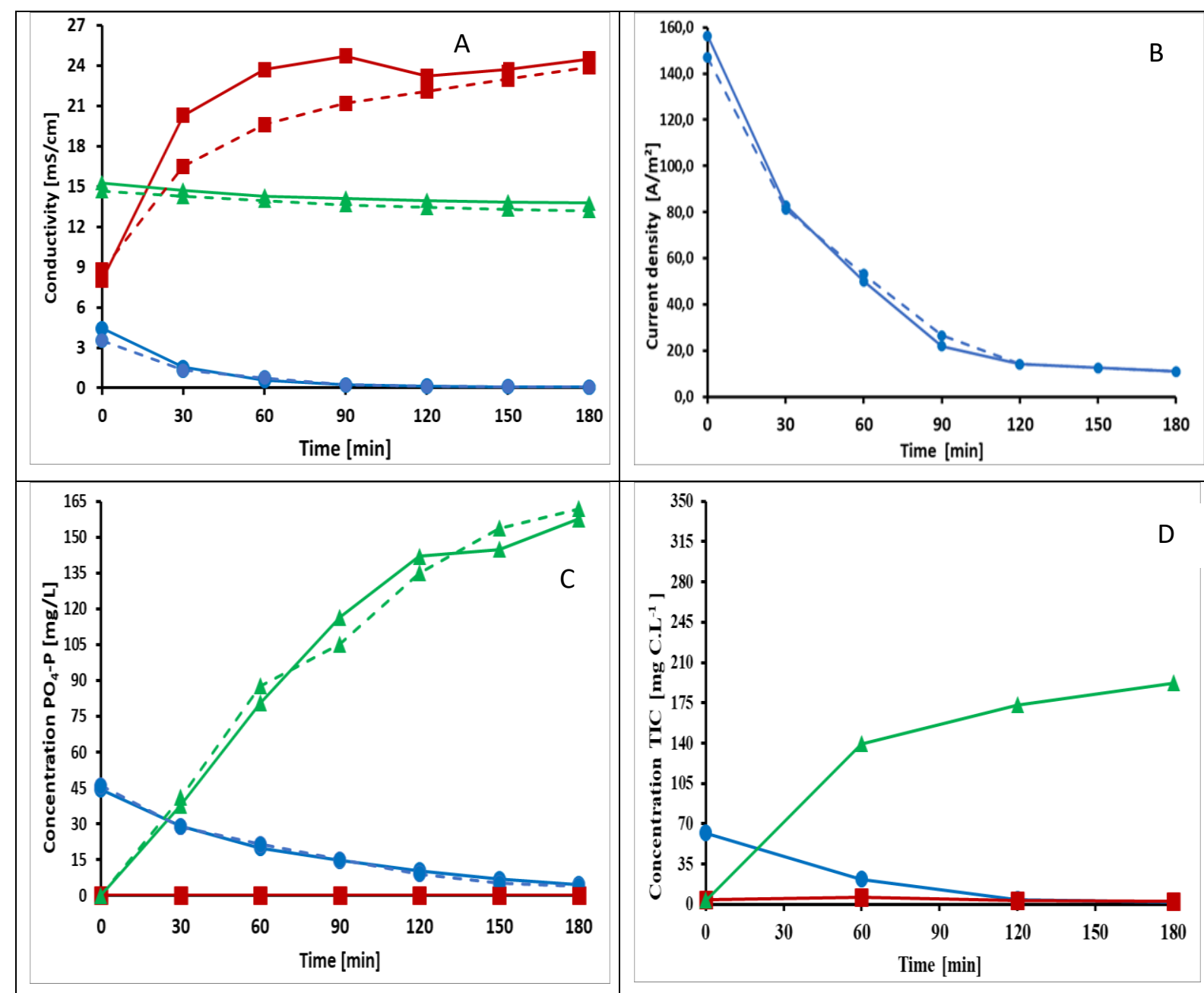

Figure 5: A: course of the conductivity in the circulating fluids: blue: feed/diluate - green: product - red concentrate. B course of the current under a constant voltage of $10 \mathrm{~V}$ in function of the time. $\mathbf{C}$ and $\mathbf{D}$ : resp. course of phosphate and TIC - colours as in A. Full lines: first experiment- dashed lines: replicate experiment.

A more quantitative way to evaluate the migration of phosphate through the PC-SA membrane is calculating how selective its transport is relative to other ions e.g. against the chloride ion, an ion with a high mobility. According to equation 2, the selective transport of some ions relative to chloride is presented in Table 3. At the end of the experiment the remaining concentration of the different ions becomes very low. Small errors in the determinations of these concentrations give rise to high variations in the standard deviations of the selectivities calculated from them.

From the table it is obvious that nitrate and chloride migrate in the same extent to the anode. Initially chloride migrates faster than sulphate, but when the feed gets exhausted from chloride, sulphate is more involved in ionic transport, e.g. after 120 minutes. The same is valid for phosphate. The current efficiency for phosphate thus increases as the experiment progresses. From the data it was calculated with formula (1) that the current efficiency for phosphate was about $6.5 \%$ in the first 90 minutes in the two experiments; in the following hour the current 
efficiency for phosphate transport increased to $11.7 \%$; see table 6 . For this calculation it was taken in consideration that the actual migrating form is $\mathrm{HPO}_{4}{ }^{2-}$; in formula (1), $z$ is two. It is also deducted from Table 3 that, relative to the transport of chloride, initially the migration of phosphate is slower than that of sulphate. The hydrated sulphate ion, which has in contrast to the monohydrogen or dihydrogen phosphate, no linked hydrogens to form hydrogen bonds with water molecules is smaller than hydrated phosphate ions and migrates faster. Indeed, a value of $0.290 \mathrm{~nm}$ for the hydrated radius of sulphate ions is reported in literature [22].

Table 3: Selective transport of nitrate, sulphate and phosphate relative to chloride. A value near zero means no selectivity. A positive value indicates preferential transport of chloride and, vice versa, a negative value indicates preferential transport of the second ion.

\begin{tabular}{|c|c|c|c|}
\hline Time interval (min) & $\boldsymbol{S}_{\mathrm{Cl}^{-} / \mathbf{N O}_{\mathbf{3}}{ }^{-}}$ & $\boldsymbol{S}_{\mathrm{Cl}^{-} / \mathbf{S O}_{\mathbf{4}}{ }^{2-}}$ & $\boldsymbol{S}_{\mathbf{C l}^{-} / \mathbf{P O}_{\mathbf{4}}{ }^{3-}}$ \\
\hline $0-30$ & $0.01 \pm 0.05$ & $0.20 \pm 0.04$ & $0.42 \pm 0.07$ \\
\hline $30-60$ & $-0.02 \pm 0.06$ & $0.23 \pm 0.02$ & $0.41 \pm 0.00$ \\
\hline $60-90$ & $-0.11 \pm 0.05$ & $0.33 \pm 0.02$ & $0.40 \pm 0.04$ \\
\hline $90-120$ & $-0.07 \pm 0.13$ & $0.52 \pm 0.08$ & $0.37 \pm 0.02$ \\
\hline $120-150$ & $-0.23 \pm 0.12$ & $0.18 \pm 0.10$ & $0.09 \pm 0.19$ \\
\hline $150-180$ & $-0.34 \pm 0.10$ & $0.08 \pm 0.11$ & $-0.02 \pm 0.26$ \\
\hline
\end{tabular}

\subsection{Screening of SA membranes.}

The previous experiment with real wastewater makes clear that the MVA membrane used at lab scale perfectly retains the phosphate ions. The concentration of phosphate in the product stream is thus, besides from the initial concentration in the feed, only dependent on the migration properties of the SA membrane. In this section several membranes are investigated on lab scale for their potential use as SA membrane in the aSED stack. For this comparison we choose for the same short batch test as described above for the reference membrane. In this way interference by fouling of the membranes is minimized and the observed differences thus solely will be the result of the performance of the membranes. The membranes that were investigated are listed in Table 1 together with some characteristics. Initial conductivity of and phosphate-P concentration in the feed were $3 \mathrm{mS} . \mathrm{cm}^{-1}$ and $45 \mathrm{mg}$. $\mathrm{L}^{-1}$. Given in Table 4 is the total decrease (in percent) of both after 3 hours.

Table 4: Survey of the membranes tested as possible alternative for the PC-SA membrane. Decrease of conductivity and of phosphate concentration during a batch experiment.

\begin{tabular}{|c|c|c|}
\hline SA membrane & \% decrease of conductivity & \% decrease of [phosphate] \\
\hline PCA PC-SA (= reference) & 98.2 & 89.71 \\
\hline PCA PC-Acid 100 & 73.4 & 0.00 \\
\hline Fumatech PAS-PET-130 & 94.7 & 53.90 \\
\hline Fujifilm Type 1 & 99.6 & 99.75 \\
\hline Fujifilm Type 10 & 98.6 & 94.17 \\
\hline PCA PC Acid 100 OT & 99.3 & 98.67 \\
\hline PCA PC 400 D & 99.1 & 96.30 \\
\hline
\end{tabular}


A good candidate for replacement for the SA membrane should combine a high desalination degree with a high removal efficiency of phosphate. From Table 4 it is clear that Fujifilm Type 1 and PC-Acid 100 OT and PC-400 D from PCA may have some potential.

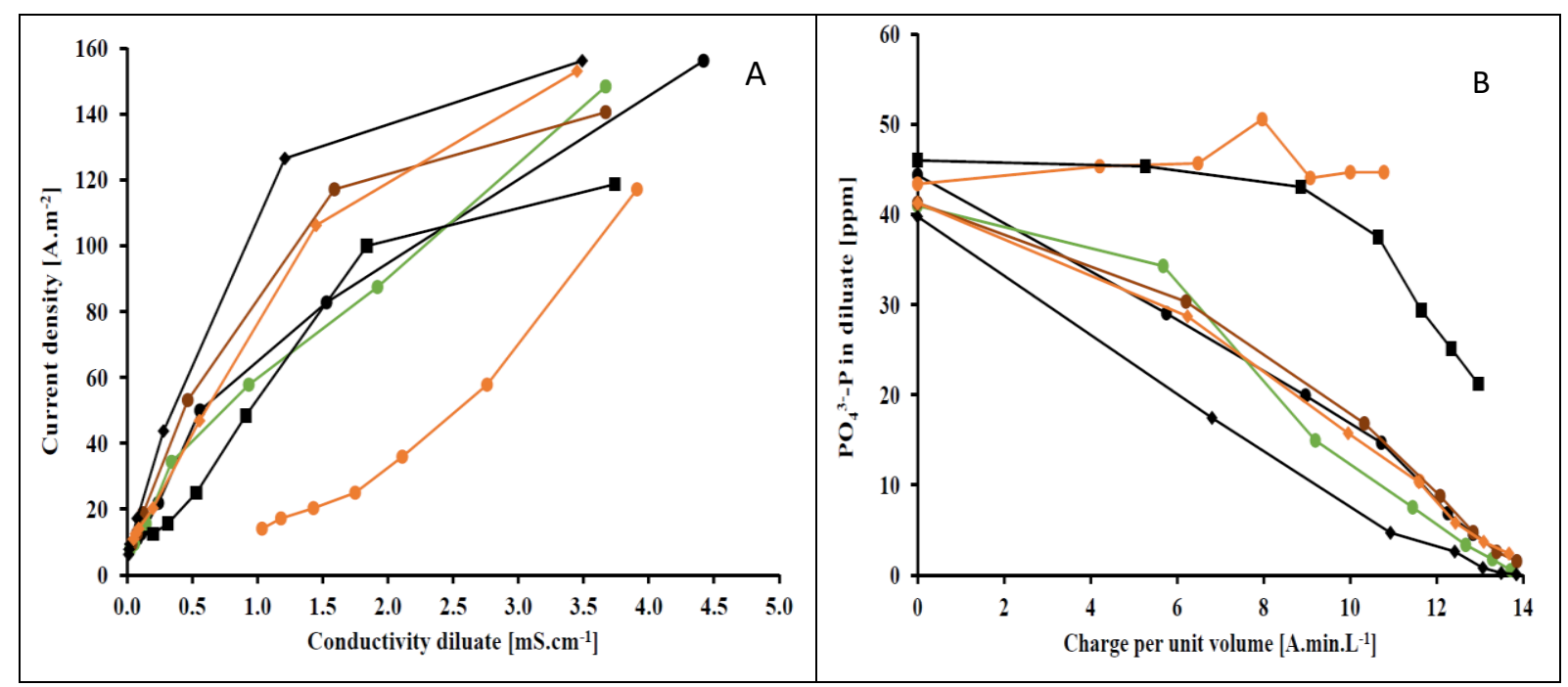

Figure 6: comparison of the effect of different SA membranes: A: correlation between the actual conductivity and the corresponding current density as an indication for the resistance of the different membranes and $\mathbf{B}$ : concentration of phosphate- $P$ in the diluate as a function of the cumulative charge that was consumed per volume. Circles : membranes from PCA (black: PC-SA; orange: PC-Acid 100; green: PC-Acid 100 OT and brown PC 400 D ); diamonds: membranes from Fujifilm (black: Type 1 and orange: Type 10) and squares: membrane from Fumatech (Fumasep PAS-PET-130).

The effect of the different membranes on the migration of ions is illustrated by Figure 6A: good membranes have a low resistance which results in a high current density for a given conductivity. Figure 6A shows that the Fujifilm membranes perform better than the standard PC-SA membrane of PCA, but also that the PC-Acid 100 OT membrane performs much better than the PC Acid 100 membrane. Since the current density varies from membrane to membrane, in Figure 6B the removal of phosphate from the diluate is presented as a function of cumulative charge transport. A membrane that is well permeable for phosphate needs less cumulative charge transport. Some membranes perform better than the PC-SA membrane especially during the first part of the experiment. It is obvious that the PC-Acid 100 and the Fumatech membrane are barely permeable for phosphate. By putting phosphate removal as function of the cumulative charge transport variations in exogenous parameters such as in ionic composition or temperature are neutralized and the observed differences are thus solely the result of variations in the performance of the membranes. Table 1 summarizes what is known about the properties of the membranes.

The selectivity of chloride transport relative to phosphate transport through the different membranes for six successive time intervals is given in Table 5. In general, a decrease of the calculated $\mathrm{S}$ value along the experiment is noticed, indicating that ionic transport as carrier for the electric transport gradually is shifting from chloride transport to phosphate transport. For Fujifilm Type 1 membrane and for PC-Acid 100 OT membrane the S value became sooner negative, after 1.5 to 2 hours, than for the other membranes, indicating that phosphate transport is sooner dominant over chloride transport. 
Table 5: The selectivity of the transport of chloride vs phosphate through the various SA membranes was calculated for 6 successive time intervals.

\begin{tabular}{|c|c|c|c|c|c|c|c|}
\hline $\begin{array}{c}\text { Time } \\
\text { interval } \\
\text { [min] }\end{array}$ & PC-SA & $\begin{array}{c}\text { PC ACID } \\
100\end{array}$ & $\begin{array}{c}\text { Fumatech } \\
\text { FAS-PET- } \\
130\end{array}$ & $\begin{array}{c}\text { Fujifilm } \\
\text { Type 1 }\end{array}$ & $\begin{array}{c}\text { Fujifilm } \\
\text { Type 10 }\end{array}$ & $\begin{array}{c}\text { PC ACID } \\
100 \text { OT }\end{array}$ & PC 400 D \\
\hline $0-30$ & 0.47 & 0.71 & 0.95 & 0.12 & 0.00 & 0.54 & 0.51 \\
\hline $30-60$ & 0.41 & 0.97 & 0.91 & 0.09 & 0.28 & 0.17 & 0.40 \\
\hline $60-90$ & 0.43 & -0.55 & 0.75 & 0.27 & 0.37 & -0.49 & 0.30 \\
\hline $90-120$ & 0.36 & 0.22 & 0.60 & -0.16 & 0.32 & -0.13 & -0.17 \\
\hline $120-150$ & 0.23 & 0.93 & 0.32 & -0.35 & 0.25 & 0.12 & 0.04 \\
\hline $150-180$ & -0.20 & 0.89 & 0.20 & -0.99 & -0.57 & -0.17 & 0.26 \\
\hline Overall value & 0.28 & 0.53 & 0.62 & -0.17 & 0.11 & 0.01 & 0.22 \\
\hline
\end{tabular}

Table 6: Current efficiency for phosphate transport with the indicated membrane as SA-membrane.

\begin{tabular}{|c|c|c|c|}
\hline TIME & PC-SA & $\begin{array}{c}\text { PC-Acid } \\
100 \text { OT }\end{array}$ & $\begin{array}{c}\text { FUJIFILM } \\
\text { TYPE 1 }\end{array}$ \\
\hline 30 & 5.54 & 2.50 & 7.28 \\
\hline 60 & 5.94 & 11.5 & 6.46 \\
\hline 90 & 6.28 & 7.04 & 2.80 \\
\hline 120 & 10.2 & 7.34 & 6.38 \\
\hline 150 & 11.7 & 5.64 & 1.64 \\
\hline 180 & 8.22 & 4.92 & 2.00 \\
\hline
\end{tabular}

Table 6 gives the current efficiency for phosphate transport with either the previously used PCSA membrane mounted in the stack as SA membrane or the candidate replacements, PC Acid 100 OT and Fujifilm Type 1. There appears to be some variation in the current efficiency for phosphate transport within each experiment, but also that this current efficiency is better with the candidate replacements. Considering that there was some starting up effect with the PCAcid OT membrane, this membrane performed better between 30 and 90 minutes than the PCSA membrane. Also, the Fujifilm Type 1 membrane performed in the first hour better than the PC-SA membrane. The relatively high current efficiency for phosphate transport at the end of the experiment with the PC-SA membrane is the consequence of the lower phosphate transport at the start of the experiment and the increasing relative concentration of phosphate in the diluate near the end of the experiment. The reverse can be said for the Fujifilm Type 1 membrane: in the first hour a relative stable part of the current (about $7 \%$ ) is used for phosphate transport and near the end of the experiment virtually no phosphate is left that can transmit current.

Further enhancement of selective transport of phosphate was aimed at by studying the influence of $\mathrm{pH}$ and voltage drop over the stack. 
In the idea that the SA membranes themselves would be somewhat selective for monovalent ions the $\mathrm{pH}$ of the wastewater was deceased to 6.2. At this $\mathrm{pH}$ phosphate mostly exist as mono charged $\mathrm{H}_{2} \mathrm{PO}_{4}{ }^{-}$; see Figure 1 .

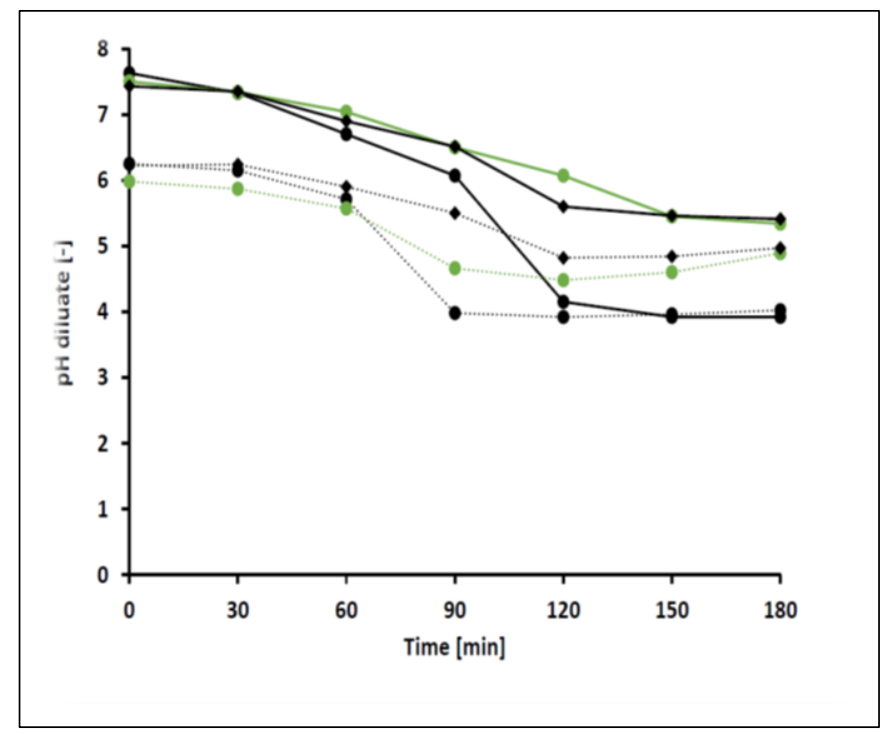

Figure 7: Course of the $\mathrm{pH}$ of the diluate starting at a $\mathrm{pH}$ of about 7.5 (full line) or 6.2 (dashed line) when either PC-SA (black - circles), PC Acid 100 OT (green - circles) or Fujifilm Type 1 (black - diamonds) membranes are incorporated in the stack as standard membrane.

Figure 7 shows the course of the $\mathrm{pH}$ in the diluate during the experiments at the original $\mathrm{pH}$ (7.5) and at $\mathrm{pH} 6.2$ when the originally used PC-SA membrane is built in the stack or one of the two possible candidate substitutes, the PC-Acid 100 OT membrane or the Fujifilm Type 1 membrane. Table 7 resumes the $\mathrm{pH}$ values of the different circulating fluids at the end of the different experiments. The $\mathrm{pH}$ of the diluate in all cases decreases. With the PC-SA membrane, the $\mathrm{pH}$ that finally was reached was 4 , independent of the starting $\mathrm{pH}$ of the feed. The same is true for the $\mathrm{pH}$ of the concentrate when the PC-SA membrane is used: independent of the starting $\mathrm{pH}$ of the diluate, the final $\mathrm{pH}$ of the concentrate decreases to about 2.5. With the two candidate substitutes, the $\mathrm{pH}$ of the concentrate only slightly decreased when the experiment started with a diluate at $\mathrm{pH} 7.5$; when the experiment started with a diluate of $\mathrm{pH} 6.2$, the $\mathrm{pH}$ of the concentrate decreased more significantly. With the PC-SA membrane in place the $\mathrm{pH}$ of the product stream increased to about 10 independent of the $\mathrm{pH}$ of the diluate at the start of the experiment. This increase of the $\mathrm{pH}$ of the product stream was not observed with the two other membranes.

Table 7: Final $\mathrm{pH}$ in the different circulating solutions using the three selected membranes under varying starting pH's of the diluate and varying voltage drops over the stack.

\begin{tabular}{|c|c|c|c|c|c|}
\hline & & $\mathrm{pH} \mathrm{7.5}$ & $\mathrm{pH} 6.2$ & $\mathrm{pH} \mathrm{7.5}$ & $\mathrm{pH} 8.0$ \\
& & $10.0 \mathrm{~V}$ & $10.0 \mathrm{~V}$ & $13.8 \mathrm{~V}$ & $13.8 \mathrm{~V}$ \\
\hline \multirow{2}{*}{ PC-SA } & Diluate & 4.0 & 4.0 & 3.5 & \\
& Product & 10.2 & 9.9 & 11.8 & \\
& Concentrate & 2.5 & 2.2 & 1.8 & \\
\hline PC ACID 100 OT & Diluate & 5.3 & 4.9 & 5.4 & 6.0 \\
& Product & 9.3 & 7.2 & 9.3 & 9.0 \\
& concentrate & 6.7 & 2.5 & 2.8 & 7.5 \\
\hline Fujifilm Type 1 & Diluate & 5.4 & 5.0 & 4.9 & 6.0 \\
& Product & 8.6 & 7.5 & 10.1 & 9.2 \\
& Concentrate & 6.4 & 3.4 & 2.6 & 7.8 \\
\hline
\end{tabular}


These results confirm the assumption, made in paragraph 3.1, that PC-SA membranes preferably transport phosphate ions in the $\mathrm{HPO}_{4}{ }^{2-}$-form, making deprotonation of $\mathrm{H}_{2} \mathrm{PO}_{4}{ }^{-}$ necessary. Both PC-Acid 100 OT and Fujifilm Type 1 membranes seem to be able to transport also more $\mathrm{H}_{2} \mathrm{PO}_{4}$-ions, making $\mathrm{pH}$-changes less necessary. This corresponds with the fact that phosphate ions migrate in an easier way through these two types of membranes.

Figure 8A shows the phosphate concentration in the diluate as function of the charge consumed by the stack. Phosphate transport did not benefit from decreasing the $\mathrm{pH}$ of the diluate, on the contrary. The phosphate concentration in the diluate that started at a $\mathrm{pH}$ of 6.2 was consistently higher than the reference experiment that started at $\mathrm{pH}$ 7.5. The same is true for the two other membranes. The lower the $\mathrm{pH}$, the higher the fraction of $\mathrm{H}_{2} \mathrm{PO}_{4}^{-}$. This implies that phosphate transport is getting more difficult. It is expected that the $\mathrm{pH}$ influence would be the most prevailing for the PC-SA-membranes, but it seems that also for the Fujifilm Type 1 membranes the $\mathrm{pH}$-effect is bigger.

Increasing the voltage had a varying effect on the phosphate transport over the membranes, as can be seen in Figure 8B. Phosphate transport through the PC Acid 100 0T increased when the voltage drop increased from $10.0 \mathrm{~V}$ to $13.8 \mathrm{~V}$. The time for $80 \%$ removal of the phosphate from the feed decreased from 87 minutes at $10 \mathrm{~V}$ to 58 minutes at $13.8 \mathrm{~V}$. This may be an interesting property when the membrane is used in practice. Phosphate transport through the PC-SA and the Fujifilm Type 1 membrane did not benefit from increasing the voltage over the stack.

Increasing the voltage over the stack at a starting $\mathrm{pH}$ of the diluate of 7.5 and with the PC-SA membrane in place, amplified the effects on the $\mathrm{pH}$ of the different circulating fluids: the $\mathrm{pH}$ of the diluate and the concentrate decreased to respectively 3.5 and 1.8 and the $\mathrm{pH}$ of the product increased to 11.8; see Table 7. Increasing the voltage to $13.8 \mathrm{~V}$ at a starting $\mathrm{pH}$ of 7.5 resulted in a more pronounced acidification of the concentrate with the two alternative membranes. However, this acidification did not occur when the experiment started with a diluate at $\mathrm{pH} 8.0$ (Table 7).

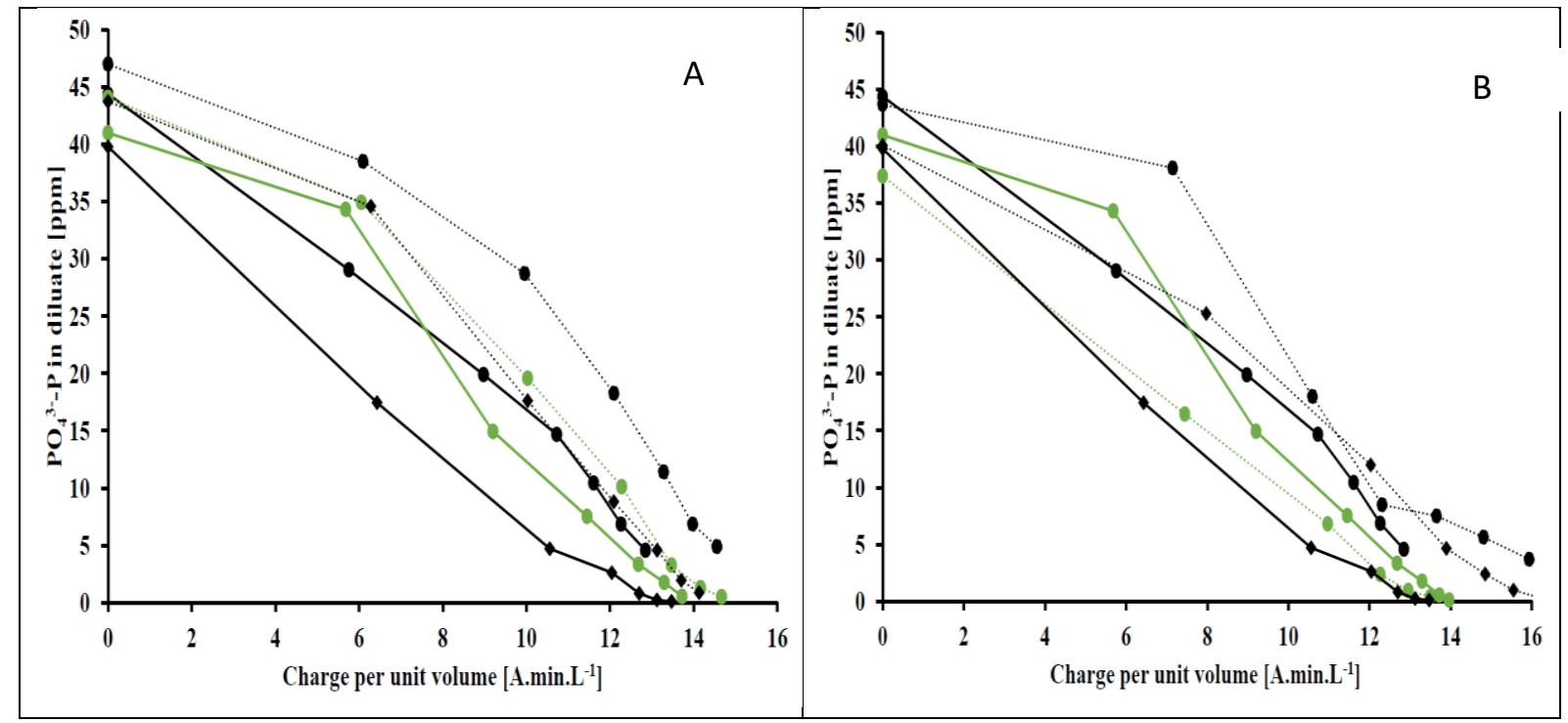

Figure 8. A: Effect on phosphate removal from the diluate of decreasing the $\mathrm{pH}$ from 7.5 (full lines) to 6.2 (dashed lines). B: effect of increasing the voltage from $10 \mathrm{~V}$ (full lines) to $13.8 \mathrm{~V}$ (dashed lines); same colour code as in Figure 7. 
All available experimental results agree with the fact that the actual migrating form of phosphate through the SA membrane is the double charged anion $\mathrm{HPO}_{4}{ }^{2-}$. Since the $\mathrm{pK}_{\mathrm{a}}$ of $\mathrm{H}_{2} \mathrm{PO}_{4}{ }^{-}$is 7.2 , at an initial of $\mathrm{pH} 6.2$ most of the phosphate occurs as $\mathrm{H}_{2} \mathrm{PO}_{4}{ }^{-}$, while at an initial $\mathrm{pH}$ of $\mathrm{pH} 8$, the majority occurs as $\mathrm{HPO}_{4}{ }^{2-}$. The hypothesis is that the permeation of $\mathrm{H}_{2} \mathrm{PO}_{4}{ }^{-}$ through the standard anion exchange membrane goes in combination with a deprotonation and an acidification of the diluate and the concentrate.

It is interesting to note that phosphate transport enhances at the end of the batch experiment when the other ions get exhausted from the feed, but also that the conditions for phosphate migration on the other hand deteriorate since the $\mathrm{pH}$ of the diluate decreases and an increasing part of phosphate occurs as $\mathrm{H}_{2} \mathrm{PO}_{4}^{-}$. The hypothesis is further that the $\mathrm{HPO}_{4}{ }^{2}$ that passed through the membrane initially re-protonates at the expense of a water molecule and the formation of a hydroxylic ion. The latter results in a $\mathrm{pH}$ increase of the product phase. But, when the experiment progresses, the $\mathrm{pH}$ increases further and the migrating $\mathrm{HPO}_{4}{ }^{2-}$ will be in equilibrium with its environment. When the starting $\mathrm{pH}$ of the diluate is $8.0, \mathrm{HPO}_{4}{ }^{2-}$ can pass the standard anion exchange membrane without deprotonation and without much change of the $\mathrm{pH}$ of as well the diluate and the concentrate as of the product.

These series of experiments demonstrate that the net result of aSED of phosphate is influenced by the type of SA membrane used. The Fujifilm Type 1 membrane and the PC-Acid 100 OT membrane are good candidates to replace the formerly used PC-SA membrane. The PC-Acid 100 OT membranes performed better when used under a higher voltage and are available for our pilot stack. Consequently, they were selected for further use.

\subsection{Pilot scale experiments to compare the performance of PC-SA membranes with the} selected PC-Acid 100 OT membranes.

Two batch experiments were then set up on pilot scale to assess if the selected standard anionexchange membrane PC-Acid $100 \mathrm{OT}$, would give rise to a faster phosphate migration from the diluate compartment to the product compartment. Figure 9A gives the conductivities of the circulating fluids in function of the time course of the experiment. After 3.5 hours, the conductivity of the diluate for the batch experiment with the PC-SA membranes has decreased from 4.23 to $0.48 \mathrm{mS} . \mathrm{cm}^{-1}$, resulting in a desalination degree of $89 \%$. For the batch experiment with the PC-Acid 100 OT membranes, the conductivity has decreased from 4.56 to $0.53 \mathrm{mS} . \mathrm{cm}^{-1}$, resulting in a desalination degree of $88 \%$. The obtained desalination degrees correspond nicely with each other and are in line with the proposed desalination degree of $90 \%$. Because of the variation in current density as a result of temperature differences between both experiments, the profiles for the diluate are also plotted as a function of the electrical charge that passed through the aSED stack; Figure 9B. The same amount of charge corresponds to the same amount of ion flux. A steeper slope thus means that the process is more efficient. Figure 9B clearly shows that the slope of both lines is virtually the same meaning that both experiments were just as efficient in terms of general desalination.

Although both experiments are almost equally efficient based upon conductivity, there is a clear difference in the course of the phosphorus content (Figure 10A). Notwithstanding the lower P concentration in the batch experiment with the PC-Acid 100 membranes, it can clearly be noted that these membranes are more efficient compared to the PC-SA membranes in removing phosphate from the feed/diluate. Over the complete experiment the phosphate concentration in the product is higher with the PC-Acid 100 OT membrane. Starting at a lower phosphate-P 
concentration, with the PC-Acid 100 OT membranes, at the end of the experiment, more phosphate-P is removed ( $\left.34 \mathrm{mg} . \mathrm{L}^{-1}\right)$ than with the PC-SA membrane $\left(26 \mathrm{mg} . \mathrm{L}^{-1}\right)$.

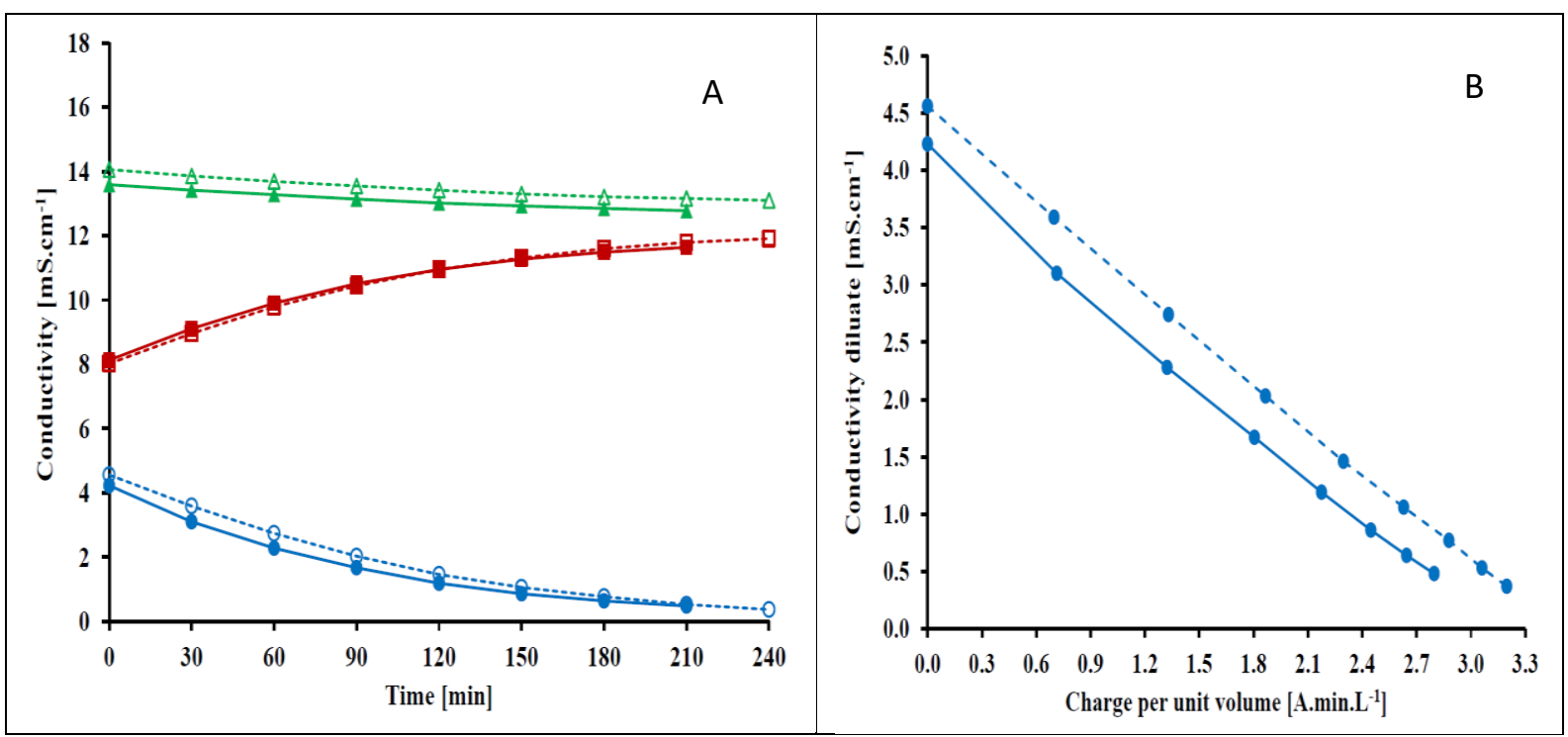

Figure 9A: Comparison of the conductivity profiles of the diluate as a function of the time; dashed lines: PCAcid 100 OT and full lines: PC-SA; blue: diluate, green: product and red concentrate. (B) as function of the electrical charge that passed the stack.

In Figure 10B the phosphate removal from the diluate (in total $200 \mathrm{~L}$ ) is plotted against the total used charge per volume. Both curves are clearly composed of two parts: after a phase of a rather limited phosphate removal, at the end the phosphate removal increases. In the first parts electrical charge is mostly carried by fast ions such as nitrate and chloride and the current

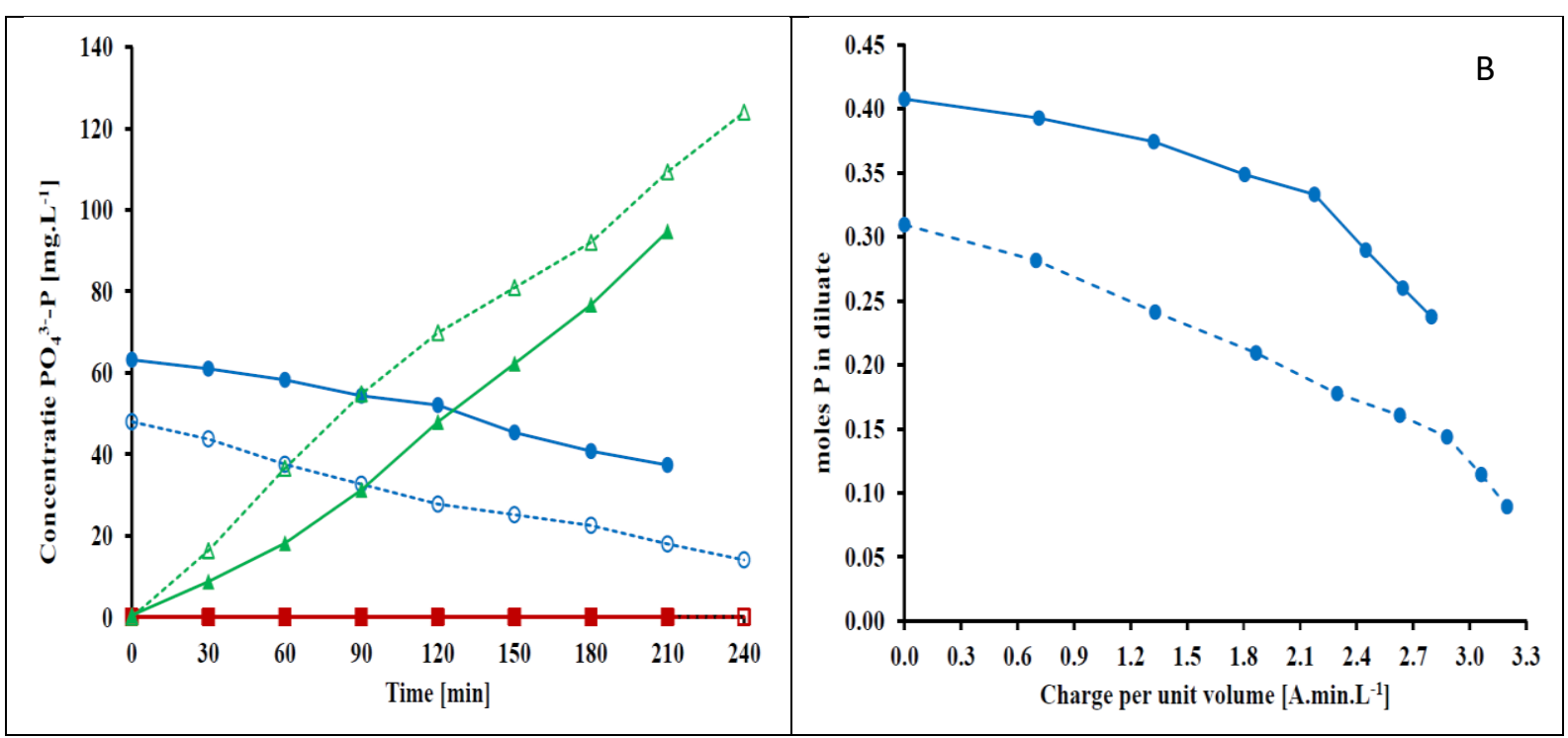

Figure 10 A: Time course of the concentration of phosphate in diluate, product and concentrate . B: Time course of the residual amount of $\mathrm{PO}_{4}{ }^{3-}-\mathrm{P}$ in the diluate as a function of the electrical charge. Colour codes as Figure 9.

efficiency of phosphate transport is rather low. When the fast ions get exhausted, phosphate ions are more involved in charge transport and the current efficiency for phosphate removal increases; see also Table 8. The slope of the first part of the curve showing the decrease of the phosphate concentration in the diluate using the PC-Acid 100 OT is noticeable steeper than the corresponding part using the PC-SA membrane. Also the second part of this curve is somewhat steeper than the counterpart for the PC-SA membrane. Both parts indicate a better phosphate 
removal when using the PC-Acid 100 OT membrane. The transition from one part to the other occurs however earlier when using the PC-SA membrane, (at 2.1 A.min. $\mathrm{L}^{-1}$ ) than when using the PC-Acid 100 OT membrane (at 2.8 A.min. $\mathrm{L}^{-1}$ ) and thus at a higher conductivity, 1.2 mS.cm ${ }^{-1}$ vs 0.7 mS.cm ${ }^{-1}$.

From Figure 10A it also clear that the MVA membrane used in the pilot stack does not allow phosphate migration, this is of utmost importance for industrial applications as this also leads to the possibility of preparing brines with enhanced concentrations of e.g. nitrate without contamination with phosphate-P.

Table 8: Course of the current intensity over the stack (A) and of the concentration of the chloride, nitrate, sulphate and bicarbonate ions in the diluate with either de PC-SA membrane or the PC-Acid 100 membrane as SA membrane in the stack during a desalination experiment at pilot scale.

\begin{tabular}{|c|c|c|c|c|c|c|c|c|c|c|}
\hline & \multicolumn{5}{|c|}{ PC-SA membrane } & \multicolumn{5}{|c|}{ PC-Acid 100 OT } \\
\hline $\begin{array}{l}\text { Time } \\
\text { (min.) }\end{array}$ & $\begin{array}{l}\mathrm{I} \\
\mathrm{A}\end{array}$ & $\begin{array}{c}\mathrm{Cl}^{-} \\
\mathrm{mg} \cdot \mathrm{L}^{-1}\end{array}$ & $\begin{array}{l}\mathrm{NO}_{3}^{-} \\
\mathrm{mg}^{-} \mathrm{L}^{-1}\end{array}$ & $\begin{array}{l}\mathrm{SO}_{4}{ }^{2-} \\
\mathrm{mg}^{-L^{-1}}\end{array}$ & $\begin{array}{c}\text { TIC } \\
\mathrm{mg} \cdot \mathrm{L}^{-1}\end{array}$ & $\begin{array}{l}\mathrm{I} \\
\mathrm{A}\end{array}$ & $\begin{array}{c}\mathrm{Cl}^{-} \\
\mathrm{mg} \cdot \mathrm{L}^{-1}\end{array}$ & $\begin{array}{l}\mathrm{NO}_{3}{ }^{-} \\
\mathrm{mg} \cdot \mathrm{L}^{-1}\end{array}$ & $\begin{array}{l}\mathrm{SO}_{4}{ }^{2-} \\
\mathrm{mg}^{-L^{-1}}\end{array}$ & $\begin{array}{c}\text { TIC } \\
\mathrm{mg} \cdot \mathrm{L}^{-1}\end{array}$ \\
\hline 0 & 5.0 & 224 & 1106 & 49 & 54 & 4.8 & 322 & 1270 & 54 & 60 \\
\hline 30 & 4.5 & 153 & 732 & 44 & I & 4.5 & 263 & 967 & 43 & / \\
\hline 60 & 3.6 & 110 & 471 & 38 & 43 & 3.9 & 206 & 604 & 33 & 50 \\
\hline 90 & 2.8 & 73 & 301 & 33 & 1 & 3.2 & 152 & 479 & 27 & I \\
\hline 120 & 2.1 & 43 & 182 & 28 & 31 & 2.5 & 104 & 325 & 22 & 36 \\
\hline 150 & 1.5 & 29 & 109 & 26 & I & 1.9 & 70 & 212 & 17 & I \\
\hline 180 & 1.1 & 18 & 66 & 22 & 20 & 1.4 & 50 & 133 & 14 & 29 \\
\hline 210 & 0.9 & 11 & 39 & 19 & 14 & 1.0 & 34 & 85 & 11 & I \\
\hline
\end{tabular}

Table 9. Time course of the current efficiencies (in \%) for the different anions applying two different SA membranes

\begin{tabular}{|c|c|c|c|c|c|c|c|c|c|c|}
\hline & \multicolumn{5}{|c|}{ PC-SA membrane } & \multicolumn{5}{c|}{ PC-Acid 100 OT } \\
\hline $\begin{array}{c}\text { Time } \\
\text { (min.) }\end{array}$ & $\mathrm{HPO}_{4}{ }^{2-}$ & $\mathrm{Cl}^{-}$ & $\mathrm{NO}_{3}{ }^{-}$ & $\mathrm{SO}_{4}{ }^{2-}$ & $\mathrm{TIC}$ & $\mathrm{HPO}_{4}{ }^{2-}$ & $\mathrm{Cl}^{-}$ & $\mathrm{NO}_{3}{ }^{-}$ & $\mathrm{SO}_{4}{ }^{2-}$ & $\mathrm{TIC}$ \\
\hline 30 & 1.7 & 23.0 & 68.3 & 1.4 & 4.9 & 3.2 & 19.0 & 56.7 & 2.7 & 4.9 \\
\hline 60 & 2.4 & 16.0 & 55.8 & 1.5 & 5.7 & 5.2 & 21.0 & 62.5 & 2.7 & 5.4 \\
\hline 90 & 4.3 & 18.0 & 45.9 & 1.8 & 9.3 & 4.8 & 23.0 & 45.1 & 1.9 & 8.9 \\
\hline 120 & 3.4 & 18.0 & 41.9 & 2.2 & 12.2 & 6.0 & 25.0 & 46.6 & 2.0 & 11.0 \\
\hline 150 & 13.0 & 12.0 & 34.9 & 1.7 & 12.6 & 4.1 & 23.0 & 44.2 & 2.5 & 10.2 \\
\hline 180 & 12.2 & 13.0 & 28.3 & 3.2 & 17.3 & 5.5 & 18.0 & 41.1 & 2.0 & 13.5 \\
\hline 210 & 12.0 & 10.0 & 23.1 & 3.4 & 28.4 & 13.1 & 20.0 & 33.6 & 2.8 & 14.9 \\
\hline 240 & & & & & & 14.9 & 18.0 & 29.5 & 2.5 & 19.8 \\
\hline
\end{tabular}

To evaluate the current efficiency of phosphate it is necessary to know the concentrations of competing anions and how they behave under the influence of the electric potential. Table 8 gives the time course of the concentrations of chloride, nitrate, sulphate and DIC along the experiment with the two different membranes, together with the decrease of the current; the time course of the phosphate concentration can be seen in Figure 10A. The interpretation is hampered by the fact that initial concentrations in the experiment with the PC-Acid 100 OT membrane are a bit higher, except for phosphate. But it is nevertheless clear that the concentration of the chloride and nitrate ions are decreasing slower in the experiment with PCAcid 100 OT membrane than in the experiment with the PC-SA membrane. Since, in general, 
the same current is flowing it is obvious that the PC-Acid 100 OT membrane allows also the migration of other ions, in particular of phosphate.

The current efficiency calculated from the concentrations and actual current is given in Table 9. The value for nitrate is clearly the highest as this is the main anion in the nitrified effluent (see also Table 2). The current efficiencies for phosphate transport through the PC-SA membrane and the PC-Acid 100 OT membrane match well with the actual changes of the phosphate concentration in the diluate as can be seen in Figure 10B: the current efficiency for phosphate increases faster at the end of the experiment where the concentrations also drop faster. From the start of the experiment to the end, the specific transport of phosphate is clearly better with the PC-Acid 100 OT membrane than with the PC-SA membrane: the values respectively increase from 3.2 to $14.9 \%$ and from 1.7 to $12.0 \%$. In the beginning the current efficiency with the PC-Acid 100 OT membrane was thus almost the double of that with the PCSA membrane. In this pilot experiment the current efficiency for phosphate transport with the PC-SA membrane was however lower than in the lab scale experiment: in the first 90 minutes, at lab scale it was $6 \%$, where it can be estimated as about $3 \%$ in this pilot experiment. Also for the PC-Acid 100 OT membrane the specific current is in this period with about $4.5 \%$ lower than at lab scale; table 6 . To the end of the experiment the transport of DIC, in practice $\mathrm{HCO}_{3}{ }^{-}$ , also increases. Contrary to what is the case for phosphate, the current efficiency for DIC increases more with the PC-SA membrane (to $28.4 \%$ ) than with the PC-Acid 100 OT membrane (to $19.8 \%$ ). The preferred migration of phosphate over DIC by the PC-Acid 100 OT membrane is an interesting property. Monballiu et al $[3,4]$ investigated the precipitation of phosphate as calcium phosphate and concluded that the precipitation of the latter was hampered by bicarbonate and led to coprecipitation of calcium carbonate. The fact that the product stream may be less contaminated with DIC when PC-Acid 100 OT membranes are used as standard membrane can thus result in calcium phosphate precipitate that is less contaminated with carbonates. Over the entire experiment, the overall current efficiency of the anions was $81 \%$ and 86\% for the batch experiment with the PC-SA and PC-Acid 100 OT membrane, respectively. Preferably, the current efficiency should be as high as possible in order to minimize the energy operating costs. The obtained current efficiencies are thus certainly acceptable for these experiments. In addition, similar current efficiencies of $90 \%$ were also reported by Zhang et al. [8] during experiments on $\mathrm{Cl}^{-} / \mathrm{SO}_{4}{ }^{2-}$ fractionation.

Separation efficiencies of different pairs of anions were calculated for their transport over either the PC-SA or the PC-Acid 100 OT membrane (by means of equation 2) over the entire duration of the experiment. These separation efficiencies are shown in Table 10. In this table, a more positive value means that the latter ion is transported slower thus that it is more retained at diluate side. To easily fractionate and concentrate phosphate in the product stream, the standard anion-exchange membranes should preferably be non-selective.

Table 10. Separation efficiencies of monovalent and bivalent anions for the batch experiments with either the PCSA membrane or the PC-ACID 100 OT membrane.

\begin{tabular}{|c|c|c|c|c|}
\hline & $\mathrm{Cl}^{-} / \mathrm{NO}_{3}{ }^{-}$ & $\mathrm{Cl}^{-} / \mathrm{DIC}$ & $\mathrm{Cl}^{-} / \mathrm{PO}_{4}{ }^{3-}$ & $\mathrm{NO}_{3}{ }^{-} / \mathrm{PO}_{4}{ }^{3-}$ \\
\hline PC-SA & -0.01 & 0.21 & 0.55 & 0.56 \\
\hline PC-ACID 100 OT & -0.05 & 0.26 & 0.26 & 0.30 \\
\hline
\end{tabular}


Since both the PC-SA and the PC-ACID 100 OT membrane are standard anion exchange membranes, in fact, no selectivity is expected between the different anion pairs. This is certainly the case for $\mathrm{Cl}^{-} / \mathrm{NO}_{3}{ }^{-}$since the value is close to zero and to a somewhat lesser extent for $\mathrm{Cl}^{-} / \mathrm{DIC}$. For these 2 anion pairs, there is no difference between the PC-SA and the PC-Acid $100 \mathrm{OT}$ membrane. However, there is a clear difference for the anion pairs $\mathrm{Cl}^{-} / \mathrm{PO}_{4}{ }^{3-}$ and $\mathrm{NO}_{3}{ }^{-} / \mathrm{PO}_{4}{ }^{3-}$. The PC-SA membrane has a clear selectivity (higher positive value) for the monovalent anions such as $\mathrm{Cl}^{-}$and $\mathrm{NO}_{3}{ }^{-}$. The PC-Acid 100 OT membrane is much less pronounced in terms of selectivity, which indicates a faster phosphate migration from the diluate. This is a confirmation of the phosphate profiles from Figure 10. The PC-Acid 100 OT membrane is therefore preferred over the PC-SA membrane for this application.

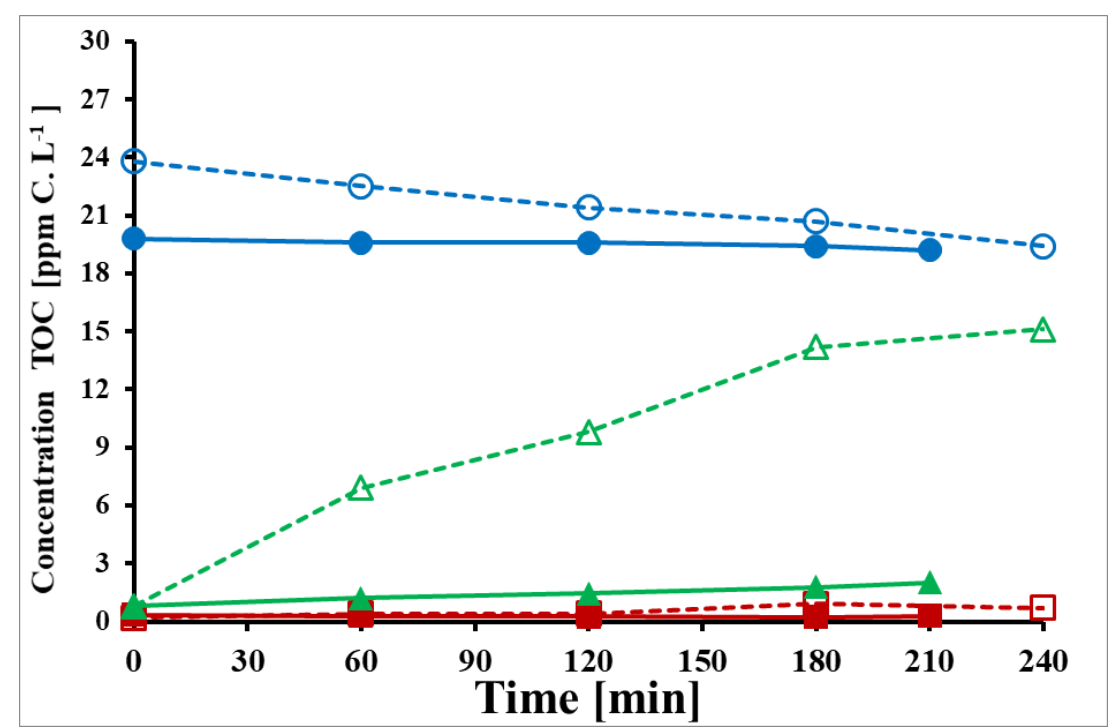

Figure 11. Comparison of the concentration profiles of TOC in the diluate, product and brine in function of the time for two types of anion-exchange membranes (PC-SA and PC-Acid 100 OT). Colour and layout as in Figures $9 \mathrm{~A}$ and $10 \mathrm{~A}$.

The different TOC behavior of both membranes is remarkable and noteworthy (Figure 11). With the PC-SA membrane, hardly any migration of TOC from the diluate to the product is observed. With the PC-Acid 100 OT membrane, on the other hand, a clear accumulation in the product is observed. This therefore implies that the TOC present in the feed water (UF filtrate of the nitrified effluent; diluate) is negatively charged.

The PC-Acid 100 OT membrane, in contrast to the PC-SA membrane, thus allows the migration of larger (charged) TOC molecules. It is therefore not surprising that phosphate, which is also a rather large ion (hydrated radius $\mathrm{HPO}_{4}{ }^{2-} / \mathrm{H}_{2} \mathrm{PO}_{4}{ }^{-}=0.327 / 0.302 \mathrm{~nm}$ [21]), migrates more easily through the PC-Acid 100 OT membrane than through the PC-SA membrane. It is noted that the use of this different standard anion exchange membranes has hardly any effect of the TOC migration towards the brine, a characteristic which is of course mainly determined by the MVA membrane.

From all the above it is evident that the PC-Acid 100 OT membrane would be a good candidate to replace the PC-SA membrane in the stacks for aSED or biselectrodialysis in the frame of phosphate recovery. Additional long-term experiments are however necessary to elucidate their performance relative to factors such as scaling and fouling when mounted in stacks used to treat real wastewaters. 


\section{Conclusions}

On lab scale and using synthetic wastewaters the aSED principle worked well in batch mode: phosphate accumulated in a substantial way in the product stream. To this end a stack was used with a PC-SA/MVA/SK membrane combination from PCA. In preliminary experiments with the pilot stack with the same membrane combination in the feed and bleed mode on real wastewater the yield of phosphate in the product stream was however too low. In this context research to optimize the process was started first at lab scale and then at pilot scale.

Initially with the same membrane combination, lab scale experiments were carried out on real wastewater, in casu nitrified and ultra-filtered UASB effluent. These experiments proved that the MVA membranes completely blocked phosphate transport and that the attainable concentrations in the product stream, besides from the concentration in the feed, only depended on the properties of the standard anion exchange membrane. It became clear that the PC-SA membrane had a low permeability for phosphate. Especially in the first part of the batch experiment the current efficiency for phosphate was low and reached a value of about $6 \%$. It also became clear that the MVA membranes had a low permeability for DIC and the preceding nitrification thus is a necessity to keep the DIC concentration in the product stream as low as possible.

Different membranes were then investigated to possibly replace the PC-SA membrane in the stack. Based on elements such as current density in function of remaining conductivity, transport over the membrane in function of the charge per volume used, current efficiency of phosphate transport and the selectivity of phosphate transport relative to the transport of other ions, the PC-Acid 100 OT membrane from PCA was selected for a pilot scale test in the batch mode.

Although the current efficiency on pilot scale was lower than on lab scale, in the first part of the batch experiment with the PC-Acid 100 OT membranes, the current efficiency for phosphate transport was about twice the value of in the experiment with the PC-SA membranes. When compared to the initially used PC-SA membrane, the preferred chloride over phosphate transport was highly reduced with the new selected membrane. The current efficiency used for DIC transport is at the end of the experiment lower when using the PC-Acid 100 OT membrane than when using the PC-SA membrane; as such the product phase with phosphate is less contaminated with DIC. The ameliorated transport of phosphate over the changed membrane went together with increased transport of organic material.

It is of course also clear that this PC-Acid 100 OT membrane would be good option to replace the PC-SA membrane during biselectrodialysis in the frame of phosphate recovery in the anion product stream.

\section{Acknowledgements}

The authors gratefully acknowledge financial support through the TETRA project "Phosphate Recovery 2.0" (HBC.2017.0029) by the Flanders Agency for Innovation \& Entrepreneurship (VLAIO). VLAKWA-VITO (Flemish Knowledge Centrum Water - Flemish Institute for Technological research), Belgapom (Professional association of the Belgian Potato Trade and Processing companies) and VeGeBe (Federation of the Belgian Vegetable Processors and Traders in Industrial Vegetables) are acknowledged for their help and encouragement during 
the project application. Agristo NV (Waregem and Wielsbeke, Belgium) is acknowledged for allowing the placement of the pilot installation on site as well as for supplying UASB effluent as feed water for the nitrification reactor and practical help. We are grateful to Paridaen NV (Oostkanp, Belgium) for practical advice on the use of UV C lamps and pomp aerators. Ekopak NV (Tielt, Belgium) is acknowledged for the UF unit, which could be used for free.

\section{REFERENCES}

1: Desmidt E., Ghyselbrecht K., Zhang Y., Pinoy L., Van der Bruggen B., Verstraete W., Rabaey K. and Meesschaert B. (2015) Global phosphorus scarcity and full-scale P-recovery techniques: a review. Critical Reviews in Environmental Science and Technology 45: 336-384.

2: Kataki S., West H., Clarke M. and Baruah D. (2016) Phosphorus recovery as struvite from farm, municipal and industrial waste: feedstock suitability, methods and pre-treatments. Waste Management 49: 437-454.

3: Monballiu A., Desmidt E., Ghyselbrecht K. and Meesschaert B.(2018) The inhibitory effect of inorganic carbon on phosphate recovery from upflow anaerobic sludge blanket reactor (UASB) effluent as calcium phosphate. Water Science and Technology 78: 2608-2615.

4: Monballiu A., Ghyselbrecht K., Crabeels X. and Meesschaert B. (2019) Calcium phosphate precipitation in nitrified wastewater from the potato-processing industry. Environmental Technology (17): 2250-2266. doi: 10.1080/09593330.2018.1439112.

5: Moerman W., Carballa M., Vandekerckhove A., Derycke D. and Verstraete W. (2009) Phosphate removal in agro-industry: Pilot- and full-scale operational considerations of struvite crystallization. Water Research 43 (7): 1887-1892.

6: Xie M., Shon H., Gray S. and Elimelech M.(2016) Membrane-based processes for wastewater nutrient recovery: Technology, challenges, and future direction. Water Research 89: 210-221.

7: Zhang Y., Paepen S., Pinoy L., Meesschaert B. and Van der Bruggen B. (2012a) Selectrodialysis: Fractionation of divalent ions from monovalent ions in a novel electrodialysis stack. Separation and Purification Technology 88: 191-201.

8: Zhang Y., Desmidt E., Van Looveren A., Pinoy L., Meesschaert B., and Van der Bruggen B. (2012b) Phosphate Recovery from Wastewater by Novel Electrodialysis. Environmental Science and Technology, 47(11): 5888-5895.

9: Liu R., Wang Y., Wu G., Luo J and Wang, S. (2017) Development of a selective electrodialysis for nutrient recovery and desalination during secondary effluent treatment. Chemical Engineering Journal 322: $224-233$.

10: Bialkovski S. (2004) Tripotic acid titration with strong base. Utah University, http://ion.chem.usu.edu/ sbialkow/Classes/3600/Overheads/H3A/H3A.html

11: Tran T.K A., Zhang Y., De Corte D., Hannes J-B., Ye W., Mondal P., Jullok N., Meesschaert, B., Pinoy, L. and Van der Bruggen B. (2014). P-recovery as calcium phosphate from wastewater using an integrated selectrodialysis/crystallization process. Journal of Cleaner Production 77: 140-151.

12: Ye Z-L., Ghyselbrecht K., Monballiu A., Rottiers T., Sansen B., Pinoy L. and Meesschaert B. (2018). Fractionating magnesium ion from seawater for struvite recovery using electrodialysis with monovalent selective membranes. Chemosphere 210: 867-876.

13: Ghyselbrecht K., Sansen B., Monballiu A., Ye Z-L., Pinoy, L. and Meesschaert B. (2019). Cationic selectrodialysis for magnesium recovery from seawater on lab and pilot scale. Separation and Purification Technology 221: 12-22.

14: Ye Z-L., Ghyselbrecht K., Monballiu A., Pinoy L.and Meesschaert, B. (2019). Fractionating various nutrient ions for resource recovery from swine wastewater using simultaneous anionic and cationic selectiveelectrodialysis. Water Research 160: 424-434.

15: Ghyselbrecht K., Monballiu A., Sansen B., Ye Z. L., Pinoy L. and Meesschaert, B. 2017 Fractionation of Bivalent ions by Selectrodialysis for Phosphate Recovery. IWA World Water Congress \& Exhibition, 16-21 sept 2018, Session TS: Resource Recovery I: Inorganic, Tokyo, Japan.

16: Zhang Y., Van der Bruggen B., Pinoy L. and Meesschaert B.(2009) Separation of nutrient ions and organic compounds from salts in RO concentrates by standard and monovalent selective ion-exchange membranes used in electrodialysis. Journal of Membrane Science 332, 104-112.

17: Sayadi I., Sistat P. and Tlili M.(2015) Assess of physical anti-scale-treatments on conventional electrodialysis pilot during brackish water desalination. Chemical Engineering and Processing. 88: 47-57. 
18:Strathmann H. (2010) Electrodialysis, a mature technology with a multitude of new applications. Desalination 264: 268-288.

19: Sansen B., Pinoy L. (sup.) and Ye Z.-L. (cosup.) (2017) Three compartment applications of electrodialysis. Thesis submitted to obtain the degree of Master in Industrial Sciences: Chemistry.

20: Kiss A., Myles T., Grew K., Peracchio A., Nelson G. and Chiu W. (2013) Carbonate and bicarbonate ion transport in alkaline anion exchange membranes, Journal of Electrochemical Society. 160 (9):994-999.

21:Huang X., He D., Tang W., Kovalsky P. and Waite T. (2017) Investigation of pH-dependent phosphate removal from wastewaters by membrane capacitive deionization (MCDI). Environmental Sciences: Water Research and Technology 3: 875-882.

22: Hussain, A., Abashar, M. and Al-Mutaz, I. (2006) Effect of ion sizes on separation characteristics of nanofiltration membrane systems. Journal King Saud University - Engineering. Sciences. 1: 1-19. 